\title{
Nano-Scale Zero Valent Iron (nZVI) Priming Enhances Yield, Alters Mineral Distribution and Grain Nutrient Content of Oryza sativa L. cv. Gobindobhog: A Field Study
}

\author{
Titir Guha ${ }^{1} \cdot$ Amitava Mukherjee ${ }^{2} \cdot$ Rita Kundu $^{1}$ \\ Received: 1 August 2020 / Accepted: 4 February 2021 / Published online: 25 February 2021 \\ (C) The Author(s), under exclusive licence to Springer Science+Business Media, LLC part of Springer Nature 2021
}

\begin{abstract}
In recent decades, nano-scale zero valent iron is reported to have plant growth enhancement capacity under laboratory conditions, but till date, there is no report to highlight its effect on the growth and yield of field-grown plants. In this study, we have evaluated the potential of nZVI priming on rice yield. A two-year field study has been conducted with different concentrations $\left(10,20,40\right.$, and $\left.80 \mathrm{mg}^{-1}\right)$ of nZVI for seed priming. The efficacy of nanopriming was compared with the hydroprimed control set. Seeds were treated for $72 \mathrm{~h}$ and sown in nursery beds and after 30 days seedlings were transplanted in the field. Root anatomy and morphology were studied in 7 days old seedlings where no changes were found. RAPD analysis also confirmed that low doses of nZVI were not genotoxic. Nanoprimed plants also had broader leaves, higher growth, biomass, and tiller number than control plants. Maximum yield was obtained from the $20 \mathrm{mg}^{-1} \mathrm{nZVI}$ primed set (3.8 fold higher than untreated control) which is achieved primarily because of the increase in fertile tiller numbers (two fold higher than untreated control). Higher values of other agronomic parameters like growth rate, net assimilation rate proved that nZVI priming enhanced photosynthetic efficiency and helped in the proper storage of photo-assimilates. All these attributed to increased accumulation of phytochemicals like starch, soluble sugar, protein, lipid, phenol, riboflavin, thiamine, and ascorbic acid in the grains. The elemental analysis confirmed that nZVI priming also promoted higher accumulations of macro and micronutrients in grains. Thus, nanoprimed seeds showed better crop performance compared to the traditional hydropimed seeds. Hence, nZVI can be considered as 'pro-fertilizer' and can be used commercially as a seed treatment agent which is capable of boosting plant growth and yield along with minimum interference to the soil ecosystem.
\end{abstract}

Keywords Nano-scale zero valent iron $\cdot$ Rice $\cdot$ Seed priming $\cdot$ Agronomic traits $\cdot$ Yield $\cdot$ Grain nutrient

\section{Introduction}

According to UN (2013), the world population is projected to reach 9.6 billion by the year 2050 . Hence, to meet food demands for the rapidly increasing world population, global grain production has to be increased by $70 \%$ by 2050 (FAO 2013). The recent global pandemic of novel coronavirus

Handling Editor: Rhonda Peavy.

Rita Kundu

rkbot@caluniv.ac.in

1 Centre of Advanced Study, Department of Botany, Calcutta University, 35, Ballygange Circular Road, Kolkata 700019, India

2 Centre for Nanobiotechnology, Vellore Institute of Technology, Vellore, Tamil Nadu 632 014, India disease (COVID-19) may slow down food production as extensive lockdowns are making it harder for the farmers to obtain fertilizers, seeds, and also restricts the movement of seasonal field laborers (Poudel et al. 2020). Hence, we must embrace future agro-productive tools which can be implemented with minimal resources. The use of nanotechnology for increasing crop productivity can be a viable strategy for farmers.

Nanotechnology can be utilized to treat seeds as it can ensure rapid seed germination and enhancement of seedling vigor which are primarily essential for efficient crop production. According to Mahakham et al. (2017), seed quality declines gradually due to storage for a prolonged period which leads to the cumulative increase of ROS. Thus, the cells undergo a decline in their antioxidant potential, which mediates various biochemical changes in seeds, resulting in loss of seedling vigor. For rice cultivation, uniform seedling 
establishment is necessary before transplantation. According to Reddy (2004), although 30 days old seedlings are considered to be ideal for transplantation, farmers are often forced to transplant older seedlings that are 40-45 days old due to delayed germination, seedling emergence, slow growth rate of seedlings, and unfavorable climatic condition (mainly lack of precipitation). Transplantation of older seedlings reduces tillering capacity which is a major yield-limiting factor in the traditional rice cultivation system. Since improvement in seed quality can be achieved by seed treatment strategies, several researchers are working on various seed treatment protocols aiming to enhance plant vigor.

Seed priming is a pre-sowing seed treatment process that involves a regulated seed hydration step before radical emergence and this technique can induce rapid seed germination, stress tolerance, and synchronized seedling establishment (Bewley et al. 2013; Paparella et al 2015). Among different seed priming methods, nutri-priming with inorganic fertilizers is considered to be quite advantageous in stimulating plant growth (Farooq et al. 2007; Rehman et al. 2011; Mirshekari, 2015). However, inorganic fertilizers (such as, $\mathrm{Fe}$ and $\mathrm{Cu}$ sulphate fertilizers)often contain a very high amount of heavy metals (like $\mathrm{Cd}, \mathrm{Cr}, \mathrm{Pb}$, and $\mathrm{Ni}$ ) which can be severely toxic for the environment and human health, and repeated use of these inorganic salts at such early stage of seedling development must be avoided (GimenoGracia et al. 1996; Otero et al. 2005). Thus, in the context of sustainable agriculture and food security, the application of nanoparticles (NPs) can be an alternative approach for nutrient delivery in plants.

Recently, several studies have been conducted on nanopriming which provided positive results. Macronutrient NP, like $\mathrm{Mg}(\mathrm{OH})_{2}$ is reported to be capable of promoting seed germination and enhance growth and photosynthetic efficiency of Zea mays seedlings (Shinde et al. 2020), priming with $\mathrm{MgO}$ NPs also stimulated seed germination and seedling vigor of Vigna radiata (Anand et al. 2020). Ca NP can also act as growth-promoting agents for plants (Yugandhar and Savithramma 2013). Existing literature is replete with several studies on nanopriming of seeds with micronutrient NPs like Zn, Cu, and Fe. Nadeem et al. (2019) and Itroutwar et al. (2019), conducted field studies with ZnO NP primed wheat and rice seeds respectively. According to their reports, Zn nutrition not only improved crop productivity but also enhanced grain nutrient qualities and aided in grain biofortification.

It can be said that the application of iron NPs can address the concerns regarding limited iron supply to plants. Foliar application of nano $\mathrm{Fe}$ (concentration $0.5 \mathrm{~g} \mathrm{l}^{-1}$ ) in black-eyed pea plants has increased seedling vigor and plant Fe content as well (Delfani et al., 2014). According to Rui et al. (2016), $\mathrm{Fe}_{3} \mathrm{O}_{4}$ NPs can be utilized as an effective iron source for Arachis hypogaea as, $\mathrm{Fe}_{3} \mathrm{O}_{4}$ NP could boost plant growth, photosynthetic efficiency, antioxidant defense mechanism, and plant Fe levels. Das et al. (2018b), has made an interesting report regarding the effects of nano-pyrite rice seed treatment and they confirmed that this nanopriming technique can be an efficient alternative to the traditional NPK fertilization technique for rice cultivation. Recently there are few reports on the growth-promoting roles of nanoscale zero-valent iron. Li et al. (2015), first reported that very low concentrations of nZVI (40-80 $\left.\mu \mathrm{mol}^{-1}\right)$ can promote peanut seed germination rate and seedling growth. Yoon et al. (2019), reported that treatment with $500 \mathrm{mg} \mathrm{nZVI} \mathrm{kg}^{-1}$ soil, can significantly enhance biomass and photosynthetic efficiency in Arabidopsis thaliana. They also found nZVI not only increased plant $\mathrm{Fe}$ content but other macro-and micronutrients such as $\mathrm{Mg}, \mathrm{P}, \mathrm{Mn}$, and $\mathrm{Zn}$ levels were increased significantly. However, till date, there is no report on field study which explores the yield enhancement potential of nZVI.

It can be said that the application of iron NPs can effectively address the global concern regarding iron deficiency which is scarcely available to the plants in aerobic and neutral $\mathrm{pH}$ environments despite being the fourth most abundant element in the lithosphere. Since iron plays an active role in plant antioxidant defense system, electron respiration, and photosynthesis, and embryogenesis, iron deficiency can hamper plant growth and productivity (Roschzttardtz et al. 2013; Grillet et al. 2013). Iron deficiency may further give rise to hidden hunger and other ailments like anemia. Researchers are already devoted to developing several biofortification techniques through conventional breeding or transgenic approaches to increase iron content in food grains. However, agronomic biofortification techniques that involve nutrient delivery through seed priming, soil, or foliar fertilizers are safer, cost-effective, and also user-friendly efficient short-term approaches to grain nutrient enhancement. Previously, we have found that seed priming with nZVI can improve seed germination, early seedling growth, water relations, photosynthetic efficiency, root metabolism, and antioxidant defense system in Oryza sativa L. cv. Gobindobhog seedlings under lab conditions in a hydroponic system (Guha et al. 2018). In addition to this, iron content was also increased in the nZVI treated seedlings; hence nZVI can be an alternative solution for providing Fe to plants.

In the present study, the yield performance of Oryza sativa L. cv. Gobindobhog seeds after priming with nZVI have been studied in detail. Since most of the researches regarding the effects of nZVI on plants are confined to shortterm in-vitro studies in hydroponics or pot culture, field studies are necessary to evaluate the long-term effects of nZVI. Our study is the first report dealing with the application of nZVI in field conditions and its potential in increasing crop productivity. Initially, after priming the seeds with different concentrations of nZVI $\left(0,10,20,40\right.$, and $\left.80 \mathrm{mg} \mathrm{l}^{-1}\right)$, 
they were transferred to the nursery bed, and after 30 days seedlings were transplanted in the field. Agronomic traits have been evaluated at different growth stages to evaluate crop performance and lastly, kernel quality was checked by estimation of phytochemicals and mineral nutrient contents. Our results indicated that nZVI priming treatment can significantly increase rice productivity and enhance grain nutrient qualities as well. All these highlight the possibility of the application of nZVI as nano fertilizer for increasing crop productivity.

\section{Materials and Methods}

\section{nZVI Synthesis and Characterization}

nZVI particles were synthesized by sodium borohydride method using ferrous sulphate $\left(\mathrm{FeSO}_{4} \cdot 7 \mathrm{H}_{2} \mathrm{O}\right)$ and EDTA $\left(\mathrm{C}_{10} \mathrm{H}_{14} \mathrm{~N}_{2} \mathrm{Na}_{2} \mathrm{O}_{8} \cdot 2 \mathrm{H}_{2} \mathrm{O}\right)$. The synthesis procedure was followed from a previous report (Ravikumar et al. 2016). nZVI was characterized using XRD (Bruker Advanced D8, Germany), UV-Visible Spectroscopy (Hitachi, U2910, Japan), Particle size analysis (NanoBrook 90Plus PALS Particle Size Analyzer, Brookhaven Instruments Corporation, USA), and TEM (Philips CM12, Netherlands). The characterization data are published in our previous report (Guha et al. 2018).

\section{Site Description}

Two-year field study was carried out in Agricultural Experimental Farm $\left(88^{\circ} 26.164^{\prime} \mathrm{E}\right.$ and $\left.22^{\circ} 22.526^{\prime} \mathrm{N}\right)$ (Fig. S1), University of Calcutta, Baruipur, South 24 Parganas in Gangetic alluvial region of West Bengal, India during the Kharif season in the year 2018 and 2019 (June to October). Field soil had following properties: $\mathrm{pH}$ : 6.75 , soil electrical conductivity: $0.011 \mathrm{dS} \mathrm{m}^{-1}$, organic carbon content: $7.4 \mathrm{~g} \mathrm{~kg}^{-1}$, Total Nitrogen: $0.73 \mathrm{~g} \mathrm{~kg}^{-1}$, Available Phosphorus: $23.35 \mathrm{~kg} \mathrm{ha}^{-1}$, Available Potassium: $150 \mathrm{~kg} \mathrm{ha}^{-1}$ (Mukherjee et al. 2019). Meteorological data during the experimental period is given in Table 1.

Table 1 Weather data at the experimental station during course of experimentation

\section{Plant Material and Growth Conditions}

Oryza sativa L. cv. Gobindobhog seeds were obtained from Rice Research Station, Chinsurah (Govt. of WB). For priming four concentrations $\left(10,20,40\right.$, and $\left.80 \mathrm{mg}^{-1}\right)$ of nZVI were freshly prepared by dispersing the particles in deionized water using ultrasonic vibration $(100 \mathrm{~W}, 40 \mathrm{kHz})$ for 30 min Mahakham et al. (2017). The control set seeds were hydroprimed using deionized water. Seeds were placed in Petri plates with moist filter papers containing $10 \mathrm{ml}$ of priming solution $\left(0,10,20,40,80 \mathrm{mg} \mathrm{l}^{-1} \mathrm{nZVI}\right)$ for 3 days in the dark, after surface sterilization with $0.2 \%$ Dithane M-45 (anti-fungal agent, Dow AgroSciences). The seeds were then transferred 7 days after germination in separate seedbeds on 20 June 2018 and 18 June 2019. 30 days old seedlings were transplanted from the nursery seedbeds to the main field. The experimental design was a randomized complete block design (RCBD) in three replications with a plot size of 1 square meter, row to row distance of $20 \mathrm{~cm}$, and plant to plant spacing of $20 \mathrm{~cm}$. The plants were grown in rain-fed irrigation conditions till maturity without any fertilizers and pesticides. Grains were harvested on $30^{\text {th }}$ October 2018 and $31^{\text {st }}$ October 2019.

\section{Nursery Seedling Characteristics}

After germination of the nanoprimed seeds, the mean emergence time (MET) and final emergence percentage (FEP) were calculated according to Ellis and Roberts (1981). The seedlings were tested for growth analysis 30 days after sowing (DAS). Shoot length (SL) and root length (RL) were recorded from 5 randomly selected seedlings.

\section{Localization of Iron in nZVI Primed Seeds}

Perl's Prussian blue (PPB) staining technique was performed according to Wang and Cuschieri (2013) to investigate the localization of iron in rice seeds. Longitudinal sections of the seeds were incubated for $30 \mathrm{~min}$ in a solution containing $2.5 \% \mathrm{HCl}(\mathrm{v} / \mathrm{v})$ and $2.5 \%$ potassium ferrocyanide (w/v). The

\begin{tabular}{|c|c|c|c|c|c|c|c|c|c|c|}
\hline \multirow[t]{3}{*}{ Months } & \multirow{2}{*}{\multicolumn{2}{|c|}{ Rainfall (mm) }} & \multirow{2}{*}{\multicolumn{2}{|c|}{$\begin{array}{l}\text { Relative humid- } \\
\text { ity (\%) }\end{array}$}} & \multicolumn{6}{|c|}{ Temperature $\left({ }^{\circ} \mathrm{C}\right)$} \\
\hline & & & & & \multicolumn{2}{|c|}{ Daily minimum } & \multicolumn{2}{|c|}{ Daily Maximum } & \multicolumn{2}{|c|}{ Daily mean } \\
\hline & 2018 & 2019 & 2018 & 2019 & 2018 & 2019 & 2018 & 2019 & 2018 & 2019 \\
\hline June & 45.68 & 101.21 & 59 & 61 & 30 & 30 & 37 & 38 & 33 & 35 \\
\hline July & 121.86 & 153.3 & 72 & 66 & 28 & 29 & 34 & 35 & 31 & 33 \\
\hline August & 147.89 & 294.9 & 76 & 75 & 27 & 28 & 33 & 33 & 30 & 31 \\
\hline September & 129.04 & 218.8 & 74 & 78 & 27 & 26 & 33 & 31 & 29 & 29 \\
\hline October & 105.1 & 194.6 & 59 & 72 & 26 & 25 & 33 & 31 & 30 & 29 \\
\hline
\end{tabular}

Source India Meteorological Department, Ministry of Earth Sciences, Government of India. (AWS ARG Networks) 
sections were examined with a simple light microscope after repeated washing.

\section{Study of Anatomical Changes of Seedling Root}

Embryonic root tips of the 7 days old seedlings were cut into $1 \mathrm{~mm}$ pieces from the tip and transverse sections of the root were made, followed by fixing the samples in $2 \%$ glutaraldehyde in $0.05 \mathrm{M}$ phosphate buffer $(\mathrm{pH} 7.2)$ for $48 \mathrm{~h}$ at room temperature. After fixation, samples were dehydrated in ethanol gradient $(30,50,70,80,90$, and $100 \%)$, sputter-coated with platinum, and observed by SEM (ZEISS EVO-MA 10; Carl Zeiss Pvt. Ltd., Oberkochen). EDX was performed simultaneously for the detection of atomic Fe on the root surface.

\section{DNA Extraction and RAPD Analysis}

$200 \mathrm{mg}$ of embryonic root tissue was collected from 7 days old seedlings primed with 0,20 and $80 \mathrm{mg} \mathrm{l}^{-1}$ nZVIfor genomic DNA extraction according to CTAB (cetyltrimethylammonium bromide)method (Doyle and Doyle 1987). The dose with the best yield and the highest treatment dose were elected for this assay. Quantity and purity of the extracted DNA were determined from Eppendorf BioSpectrometer ${ }^{\circledR}$ Basic with $\mu$ CUVETTE $^{\circledR}$ and DNA integrity was checked by gel electrophoresis on $0.8 \%$ Agarose gel (Fig. S2). RAPD analysis of isolated DNA was performed using 10 random primers among which 6 produced reproducible bands (OPA2-5'-TGCCGAGCTG-3', OPA-3-5'-AGTCAGCCAC3', OPA-4-5'-AATCGGGCTG-3', OPA-5-5'-AGGGGT CTTG-3', OPA-9-5'-GGGTAACGCC-3', OPA-10-5'GTGATCGCAG-3'). The total reaction mixture was $20 \mu \mathrm{L}$ in volume having $50 \mathrm{ng}$ DNA, $1 \times$ reaction buffer, $2.5 \mathrm{mM}$ $\mathrm{MgCl}_{2}, 100$ pmoles of decamer primer, $0.2 \mathrm{mM}$ dNTPs, and 1 U Taq DNA polymerase (Promega, USA). After amplification by PCR, the RAPD products were analyzed electrophoretically in a $1.8 \%$ agarose gel, and for observing and photographing the gel, ultraviolet (UV) trans-illuminator, and gel documentation system was used.

The amplified bands were primarily scored based on the presence or absence of the band (binary scoring, 0 and 1) against the negative (untreated) control.

Genomic template stability (\%) among nZVI primed seedlings was calculated from the formula used by Atienzar and Jha (2006):

$\operatorname{GTS}(\%)=\left(1-\frac{a}{n}\right) \times 100$,

where $a$ is the average number of the polymorphic band (new bands appeared or disappeared compared to their nontreated control) and $n$ is the total band number noted in the control.

\section{Study of Agronomic and Yield Parameters}

After maturity, rice plants from each treatment plot were manually harvested and observations regarding agronomic traits and yield components were recorded following the standard procedures. Leaf area was calculated using the length width method according to the formula: Leaf area $=0.75 \times$ Leaf length $\times$ Leaf width proposed by Palaniswamy and Gomez (1974). Agronomic parameters like absolute growth rate (AGR), crop growth rate (CGR), and net assimilation rate (NAR) were calculated for three different harvest points (30,60, and 130 DAS) according to Ghule et al. (2013) and Hunt (1979).

Plants were sun-dried to determine grain yield. Total panicles per plant and panicle length were recorded for each treatment. Filled and unfilled grains were separated and counted from each panicle to obtain grain filling percentage. 100-grain weight was recorded by weighing randomly sampled 100 filled grains.

\section{Quantitative Analysis of Grain Phytochemicals}

After maturity harvested rice grains from each treatment plot were collected for quantification of phytochemicals produced as a result of primary and secondary metabolism.

\section{Assay of Soluble Sugar and Starch}

$1 \mathrm{~g}$ of powdered rice grain sample was at first boiled in $80 \%$ aqueous methanol for $15 \mathrm{~min}$ in water-bath. Alcoholic extract was taken for colorimetric assay of total sugar estimation with the phenol-sulphuric acid reagent. The residue obtained after extraction was dried and boiled with $3 \% \mathrm{HCl}$ for $3 \mathrm{~h}$ in the water bath for acid hydrolysis of starch. The glucose released from starch hydrolysis was estimated again by phenol-sulphuric acid reagent and the value of glucose was converted to starch by multiplying with a factor of 0.9 (Das et al. 2018a).

\section{Protein Content Determination}

The total protein content from $1 \mathrm{~g}$ powdered grain was determined by using Bradford's method. $100 \mu \mathrm{l}$ of the sample extract was estimated according to Lowry et al 1951. 


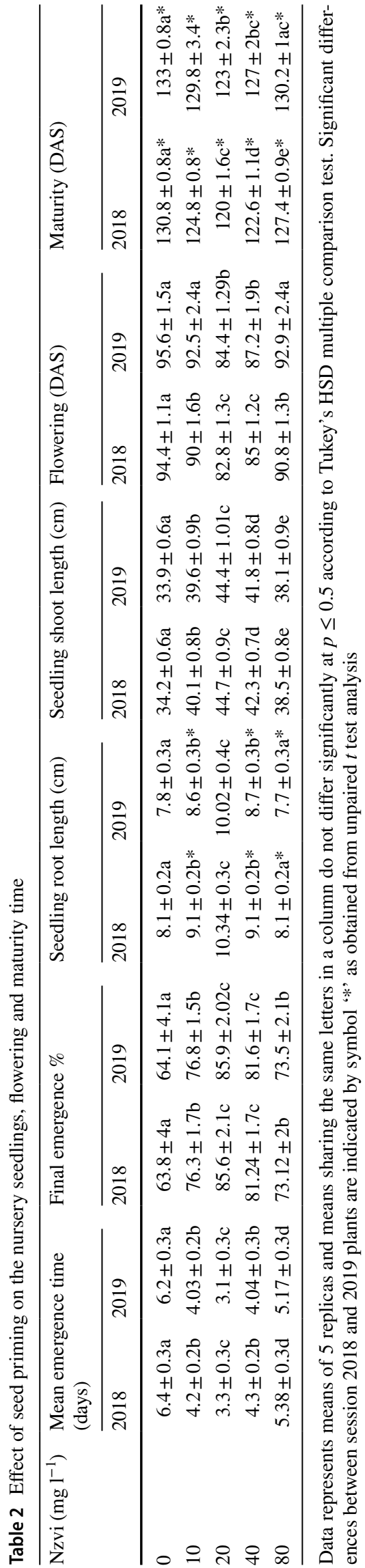

\section{Total Lipid Estimation}

Lipid estimation of rice grains was done by chloroform-methanol extraction procedure according to Bhattacharyya and Roy (2018).

\section{Phenol Estimation}

Phenol extraction was done by blending $1 \mathrm{~g}$ of powdered rice samples with $10 \mathrm{ml} 80 \%$ ethanol. After extraction $200 \mu \mathrm{l}$ of the sample extract, was mixed with $800 \mu$ FolinCiocalteu reagent and $2 \mathrm{ml}$ of $7.5 \%$ sodium carbonate added. After dark incubation for $30 \mathrm{~min}$, absorbance was taken at $765 \mathrm{~nm}$ (Su et al. 2007).

\section{Ascorbic Acid Estimation}

$0.1 \mathrm{~g}$ rice grain sample was homogenized with $1.5 \mathrm{ml} 10 \%$ TCA at $4{ }^{\circ} \mathrm{C}$ and centrifuged at $3000 \times g$ for $5 \mathrm{~min}$. The final assay mixture contained $0.5 \mathrm{ml}$ supernatant, $0.5 \mathrm{ml} \mathrm{DNPH}$ reagent (2\% DNPH, and $4 \%$ thiourea in $9 \mathrm{M}$ sulphuric acid). After $3 \mathrm{~h}$ of incubation at room temperature, $2.5 \mathrm{ml}$ of $85 \%$ $\mathrm{H}_{2} \mathrm{SO}_{4}$ was added and absorbance was recorded at $530 \mathrm{~nm}$ after $30 \mathrm{~min}$ (Okolie et al. 2014).

\section{Riboflavin Content}

For riboflavin estimation, $1 \mathrm{~g}$ powdered rice grain was extracted with $50 \%$ ethanol and after filtration $2.5 \mathrm{ml} 5 \%$ $\mathrm{KMnO}_{4}$ was added followed by the addition of $2.5 \mathrm{ml} 30 \%$ $\mathrm{H}_{2} \mathrm{O}_{2}$ solution. The extract is then heated at $80{ }^{\circ} \mathrm{C}$ on a water-bath for $30 \mathrm{~min}$. Riboflavin was quantified after adding $1 \mathrm{ml} 40 \% \mathrm{Na}_{2} \mathrm{SO}_{4}$ absorbance was recorded at $510 \mathrm{~nm}$ according to Nandagoapalan et al. (2016).

\section{Thiamine Content}

Thiamine extraction was done from $1 \mathrm{~g}$ of powered grain sample by mixing with $10 \mathrm{ml} 20 \%$ ethanolic $\mathrm{NaOH}$. After filtration of the extract $1 \mathrm{ml}$ filtrate was mixed with $1 \mathrm{ml}$ $2 \% \mathrm{~K}_{2} \mathrm{Cr}_{2} \mathrm{O}_{7}$ solution and absorbance was recorded at $360 \mathrm{~nm}$ (Bhattacharyya and Roy 2018).

\section{Estimation of Macro and Micro-nutrient Contents by ICP-AES}

After harvest, rice root, shoot and grains were dried in an oven at $80{ }^{\circ} \mathrm{C}$ for $48 \mathrm{~h}$. The oven-dried plant parts of each were then ground into powder. About $0.1 \mathrm{~g}$ of the ground samples were weighed and digested with a tri-acid mixture of $\mathrm{HNO}_{3}: \mathrm{HCl}: \mathrm{HClO} 4(4: 2: 1 \mathrm{v} / \mathrm{v})$, and the resultant solutions were diluted to $25 \mathrm{ml}$ with deionized water. The concentration of macronutrients $(\mathrm{Ca}, \mathrm{Mg}, \mathrm{P}, \mathrm{K}$, and $\mathrm{S})$ and 


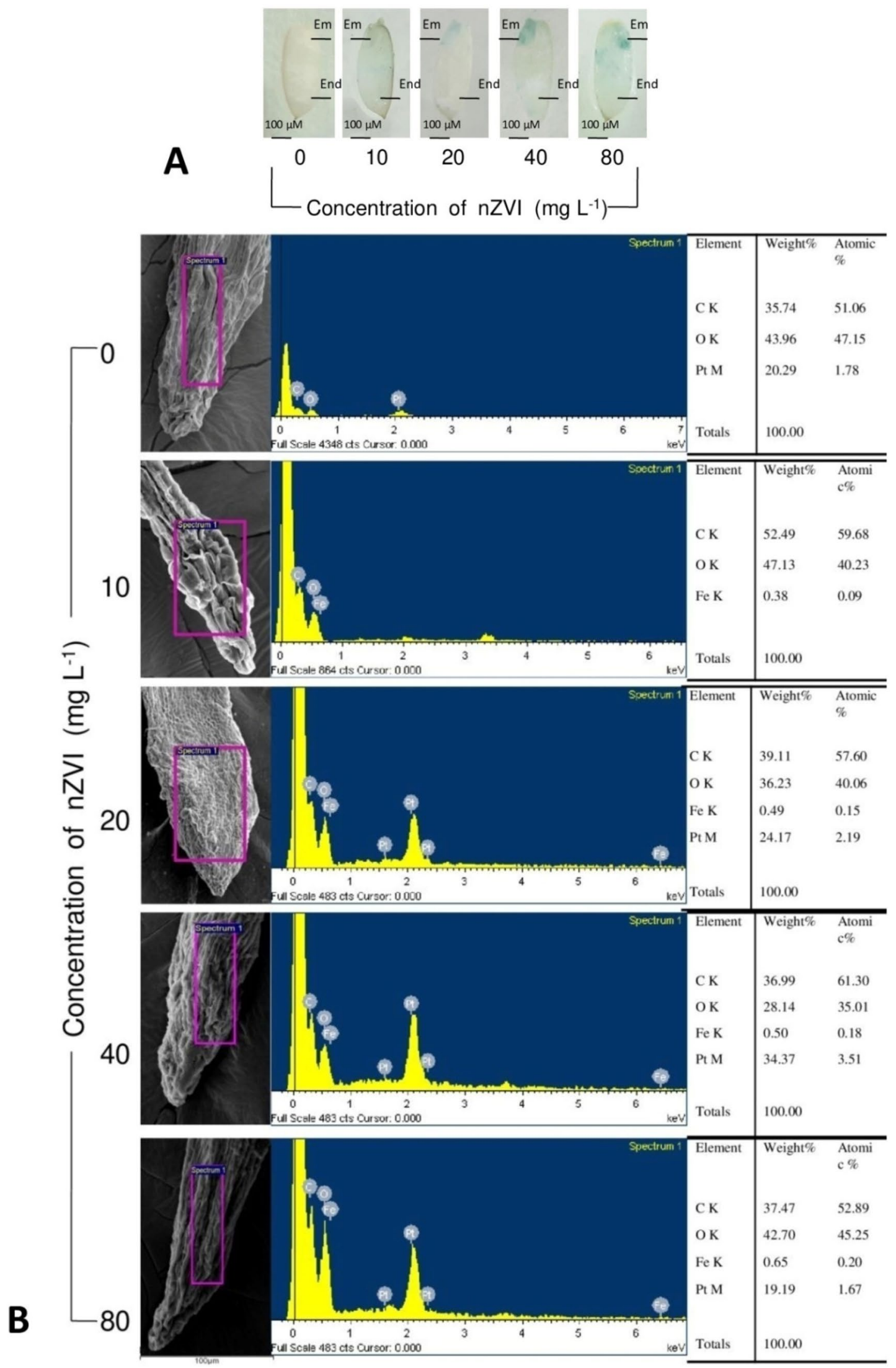

Fig. 1 a Localization of iron in the embryonic region of nZVI primed seeds after Perl's Prussian blue staining. (EM embryo, End endosperm). b EDX data of root tip surface of 7 days old seedlings treated with $0-80 \mathrm{mg}^{-1} \mathrm{nZVI}$ 


\section{Concentration of $\mathrm{nZVI}\left(\mathrm{mg} \mathrm{L}^{-1}\right)$}

10

\section{0}

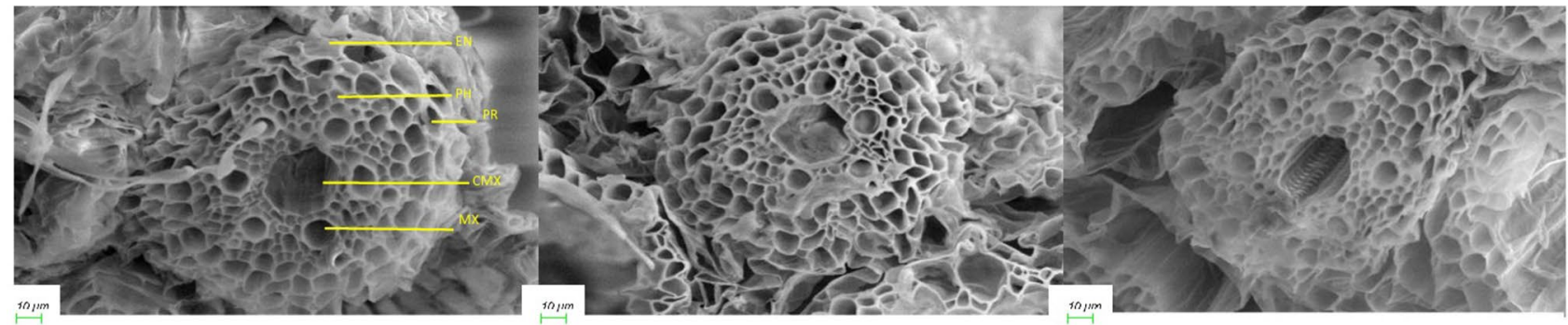

Concentration of $\mathrm{nZVI}\left(\mathrm{mg} \mathrm{L}^{-1}\right)$

40

80

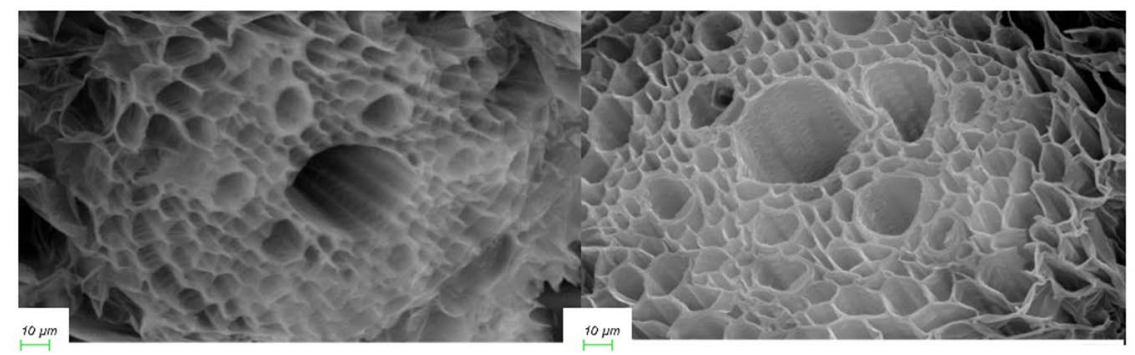

Fig. 2 Scanning electron micrograph of 7 days old rice seedlings A, B, C, D, and E represents control, 10, 20, 40, and 80 mg $1^{-1} \mathrm{nZVI}$ primed seedling root vascular tissue after transverse sections ( $E N$ endodermis, $P R$ pericycle, $P H$ phloem, $M X$ metaxylem, $C M X$ central metaxylem)

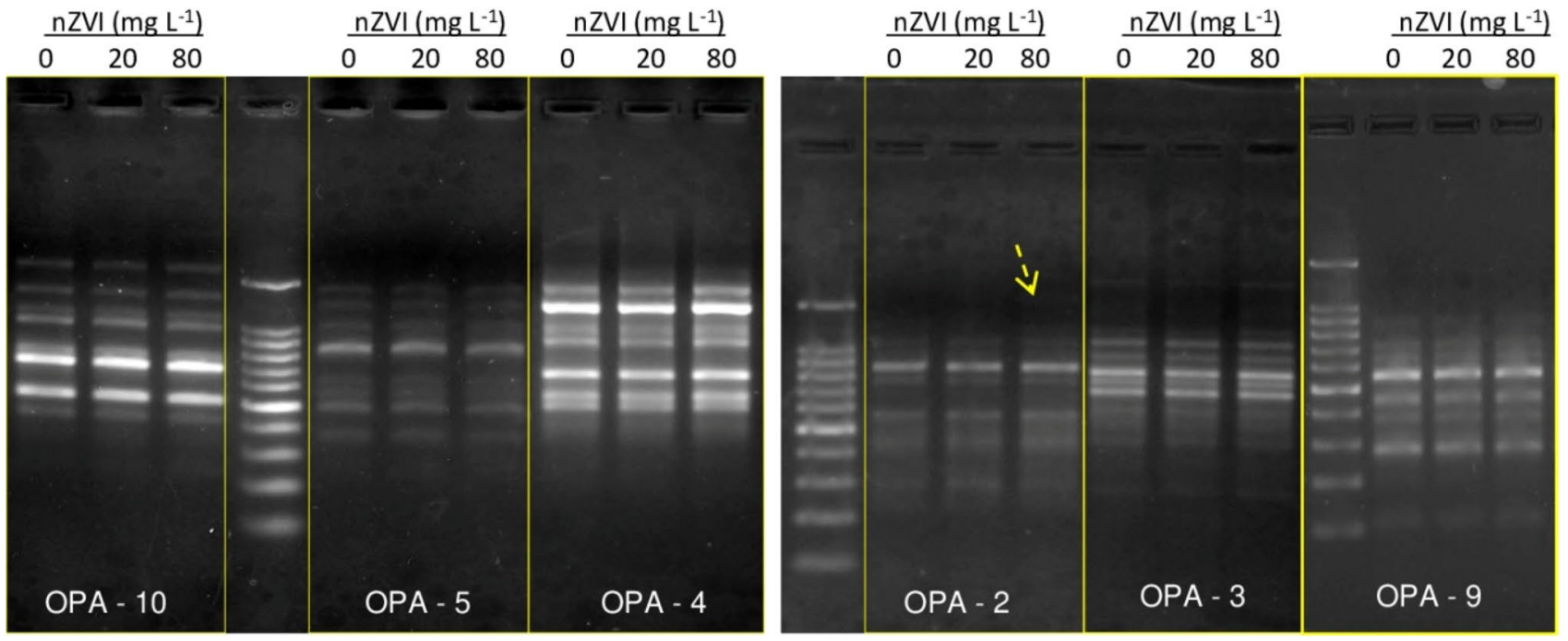

Fig. 3 Influence of nZVI treatment on RAPD profiles of 7 days old rice root tissue ( $>$ indicates the disappearance of the band)

micro-nutrients ( $\mathrm{Fe}, \mathrm{Cu}, \mathrm{Mn}, \mathrm{Zn})$ and cadmium were determined by using Inductively Coupled Plasma-Optical Emission Spectroscopy (ARCOS, Spectro, Germany).

\section{Partition Quotient of Nutrients}

Partitioning of minerals within rice plants was also checked. Changes of mineral content in each tissue were normalized to changes in each tissue's weight, relative to the whole plant dry weight (DW). The DW of each organ was calculated as a percentage of total plant DW and the mineral content of each 

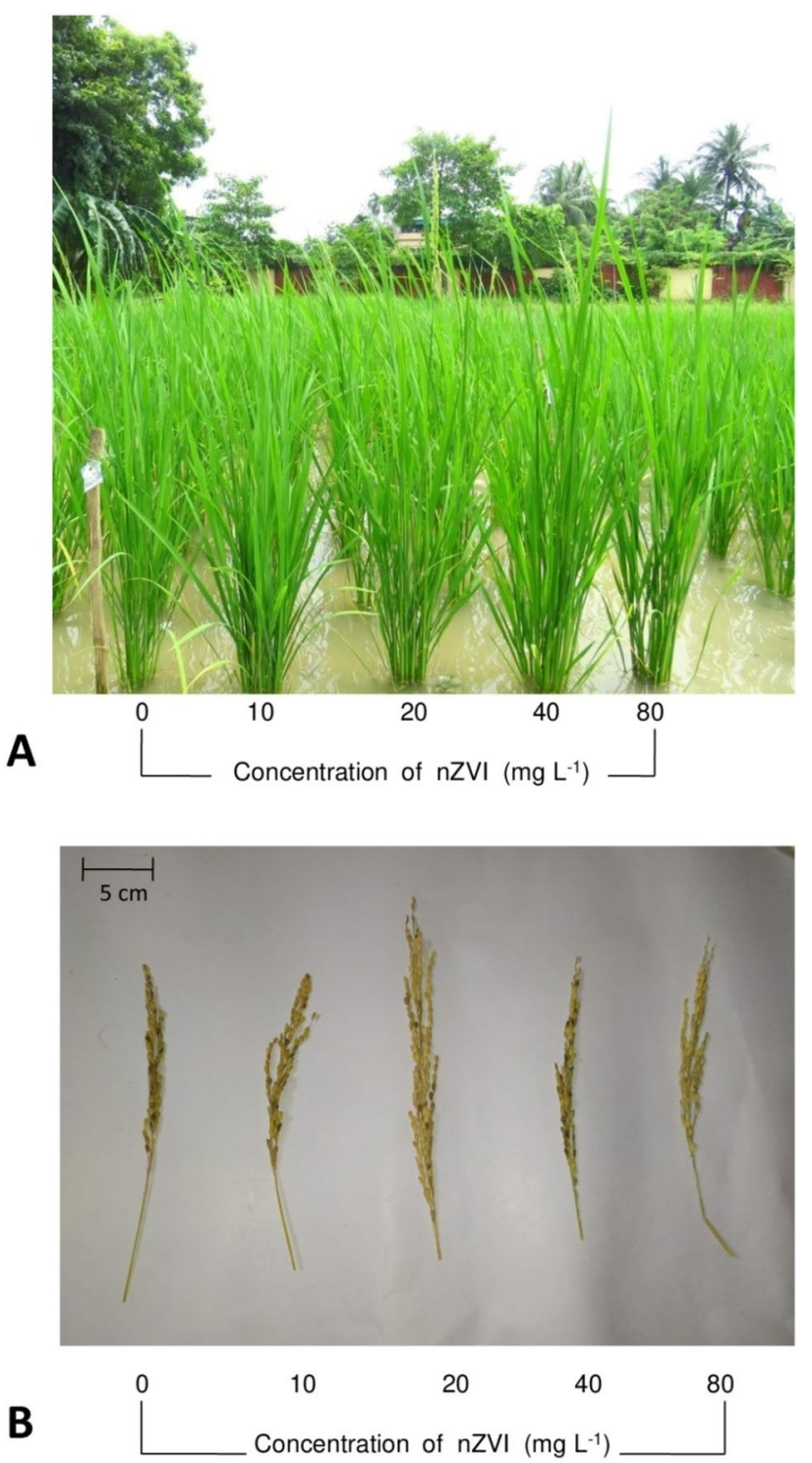

Fig. 4 Photographic images of a 60 days old rice seedlings and b panicles of $0-80 \mathrm{mg} \mathrm{l}^{-1} \mathrm{nZVI}$ primed sets

organ was calculated as a percentage of total plant mineral content. Finally, normalized partitioning of each mineral within the plant or the partition quotient (PQ) was calculated by dividing each organ's percentage mineral content by its percentage DW and multiplying by 100 (Waters and Grusak 2008).

\section{Statistical Analysis}

Statistical analysis was conducted using IBM SPSS Statistics Version. 23. Significant differences between different nZVI treatments were determined using One-way ANOVA followed by the Tukey test. A significant difference in plant responses based on the year of study was determined by $t$ test. The probability of $p \leq 0.05$ was considered to be statistically significant. Pearson's correlation analyses were carried out using two significance levels $(p \leq 0.05$ and 0.01$)$.

\section{Results}

\section{Rainfall Variation During Growth Stages}

Rainfall and temperature ranges during the growing seasons are presented in Table 1 . The average temperature range during the growth session of 2018 and 2019 varied around $31 \pm 2{ }^{\circ} \mathrm{C}$. However, rainfall distribution differed significantly in the 2 years. During the vegetative growth phase, average rainfall was $134 \mathrm{~mm}$ and $224 \mathrm{~mm}$, precipitation level during booting was $147 \mathrm{~mm}$ and $294 \mathrm{~nm}$, and before maturity average rainfall was $105 \mathrm{~nm}$ and $194 \mathrm{~nm}$ respectively in the year 2018 and 2019. The average sunshine level during the heading and maturity stage was also significantly lower in 2019 compared to that of 2018.

\section{Nursery Seedling Characteristics}

Priming with nZVI showed significant effects on MET, FEP, and seedling growth (Table 2). Seed priming with different concentrations of nZVI (10-80 $\left.\mathrm{mg} \mathrm{l}^{-1}\right)$ could significantly reduce the MET of seeds. Maximum reduction of MET was observed upon seed priming treatment with $20 \mathrm{mg} \mathrm{l}^{-1}$ nZVI solution while FEP increased significantly by 1.3 fold over the control set. At the same time, seedling growth also increased upon nanopriming. Compared to the control hydroprimed sets, shoot length increased by $1.17,1.3,1.23$, and 1.12 fold, and root length increased by $1.12,1.27$, and 1.12 fold in plants treated with $10,20,40$, and $80 \mathrm{mg} \mathrm{l}^{-1}$ nZVI, respectively. However, the root length of seeds primed with $80 \mathrm{mg} \mathrm{l}^{-1} \mathrm{nZVI}$ was similar to that of the hydroprimed control set (Table 2).

Longitudinal sections of rice seeds primed with nZVI for $72 \mathrm{~h}$, showed bright blue color mainly near the embryonic region of the seeds, confirmed presence of iron, and the intensity of blue color increased in a dose-dependent manner (Fig. 1a). Scanning electron micrographs revealed the cellular details of root vascular bundles of nZVIprimed and unprimed rice seedlings. The cells were more or less intact

Fig. 5 Influence of seed priming with different concentrations of nZVI on a plant height, b leaf area, $\mathbf{c}$ effective tiller number, $\mathbf{d}$ biomass. of rice plants after maturity. Data represent the mean of five replicates and error bars represent standard error. Means with the same letters are not significantly different (Tukey's HSD multiple comparisons at $p \leq 0.05$ ). Significant differences between session 2018 and 2019 plants are indicated by symbol '*' as obtained from unpaired $t$ test analysis 

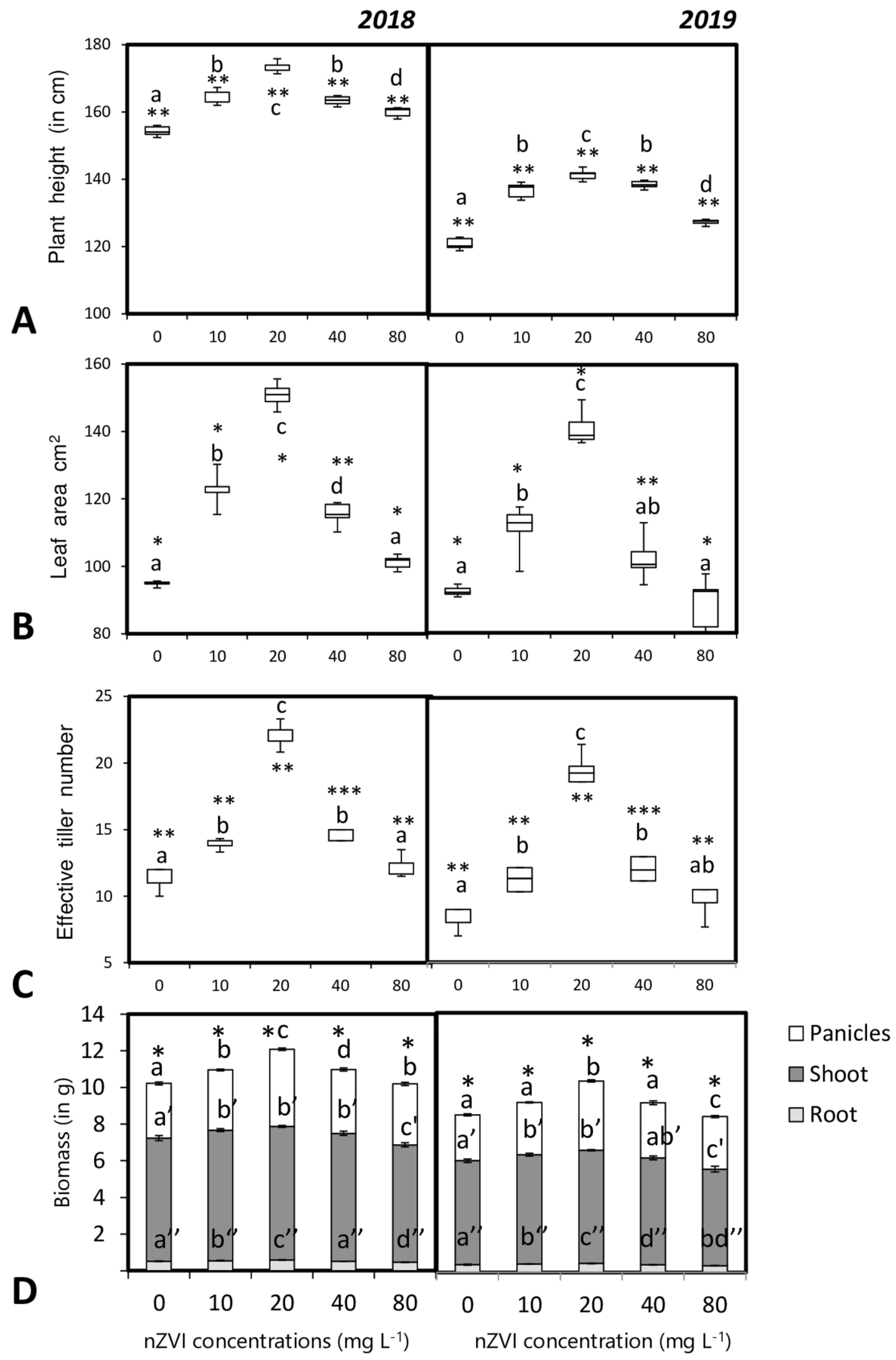
with regular shape and size. In the nZVI primed seedlings, there were no morphological alterations near the root tip region. EDX analysis confirmed the depositions of atomic iron on the root surface. The amount of internalized iron was proportional to the concentration of nZVI and control seedlings had shown no iron depositions (Fig. 1b). The transverse section of the root also revealed no damage in internal root tissues (Fig. 2).

RAPD was performed to evaluate genotoxic impacts of nZVI in terms of induction of DNA damage in the embryonic root tissue of nZVI primed seedlings with respect to untreated seedlings. Data obtained from RAPD profiles showed that there was no significant difference in banding patterns in seedlings treated with $20 \mathrm{mg} \mathrm{l}^{-1}$ nZVI. Compared to 57 amplified bands, only 1 new band appeared with the use of the primer OPA- 2 in the $80 \mathrm{mg} \mathrm{l}^{-1}$ nZVI primed seedlings and GTS\% decreased to $98.25 \%$ (Fig. 3).

\section{Agronomic Traits and Growth Analysis}

Nanopriming induced significant changes in agronomic and yield-related parameters (Fig. 4a and b). Firstly, the duration of flowering and maturity was significantly less compared to that of the untreated control. Minimum days for

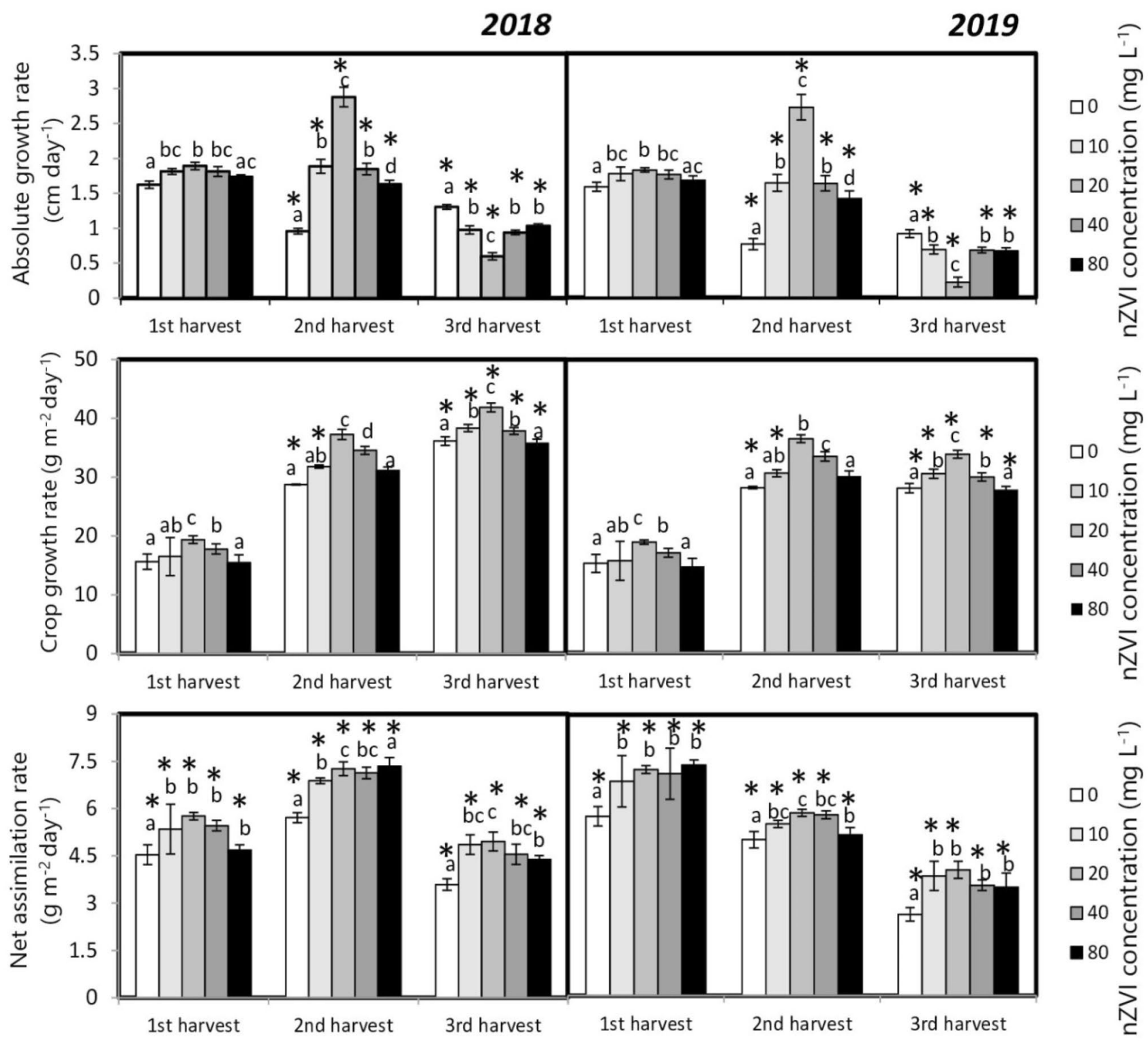

Fig. 6 Influence of seed priming with different concentrations of nZVI on a AGR, b CGR, $\mathbf{c}$ NAR of rice plants after maturity (1st harvest - on 30 DAS, 2nd harvest - on 60 DAS, 3rd harvest - at maturity). Data represent the means of five replicates and error bars repre- sent standard error. Means with the same letters are not significantly different (Tukey's HSD multiple comparisons at $p \leq 0.05$ ). Significant differences between session 2018 and 2019 plants are indicated by symbol ' $*$ ' as obtained from unpaired $t$ test analysis 
Fig. 7 Influence of seed priming with different concentrations of nZVI on panicle characters like a Panicle number per $\mathrm{m}^{2}$, b panicle length, c panicle weight, $\mathbf{d}$ total seed per panicle. Data represent the mean of five replicates and error bars represent standard error. Means with the same letters are not significantly different (Tukey's HSD multiple comparisons at $p \leq 0.05)$. Significant differences between session 2018 and 2019 plants are indicated by symbol '*' as obtained from unpaired $t$ test analysis
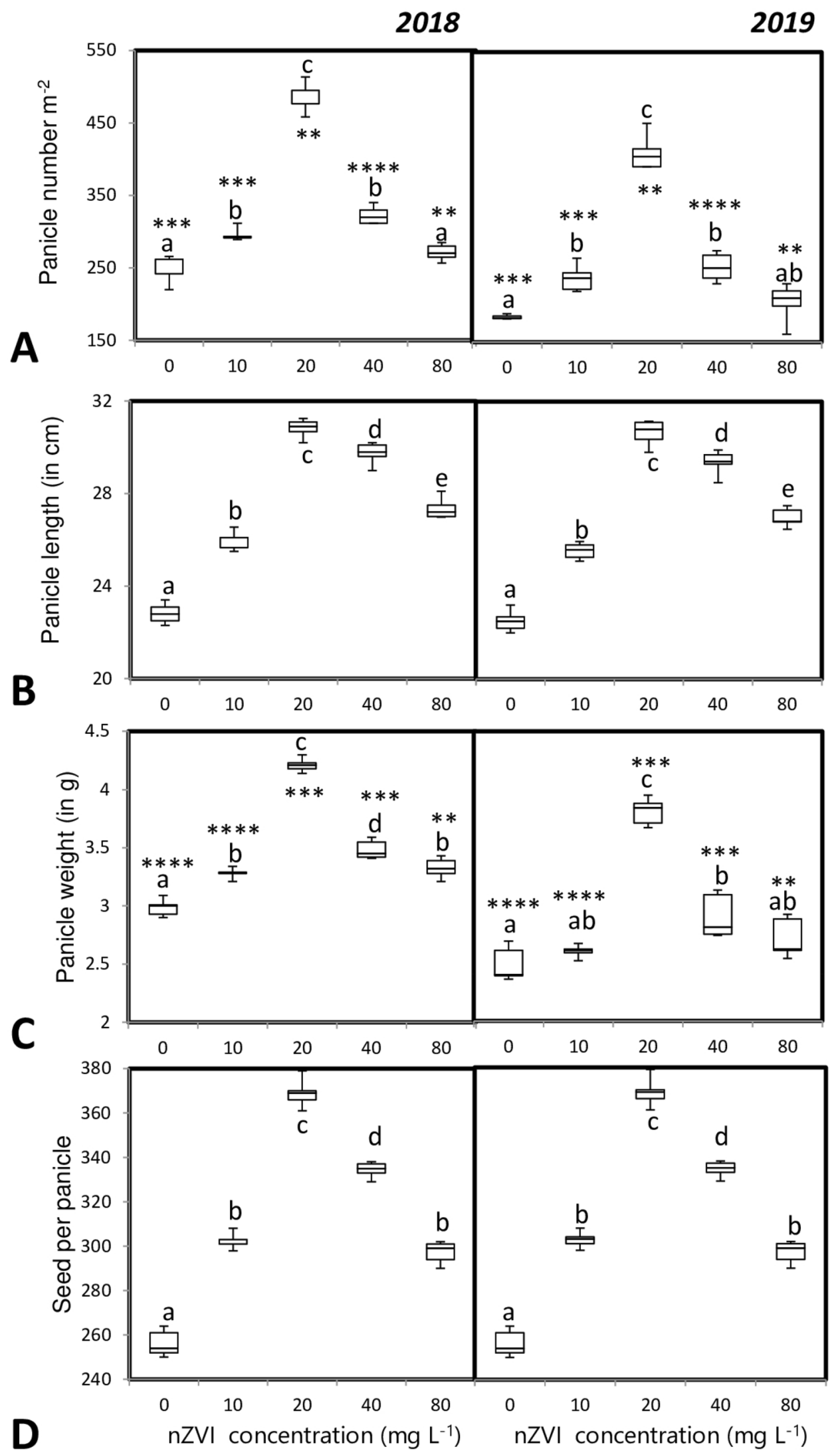


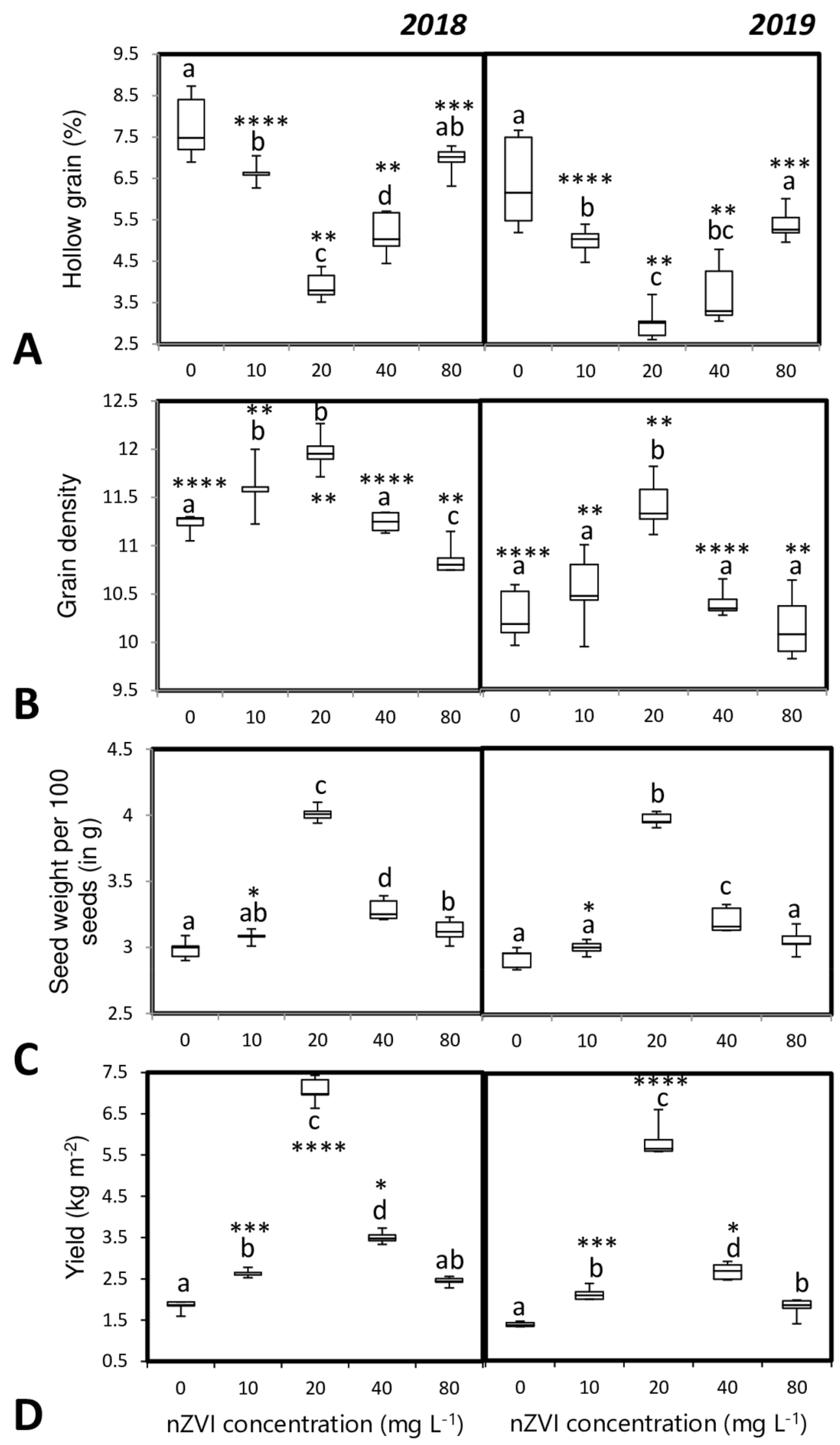


4Fig. 8 Influence of seed priming with different concentrations of nZVI on yield-related traits; a percentage of hollow grains, $\mathbf{b}$ grain density, c seed weight per 100 seeds, d.Yield $\left(\mathrm{kg} \mathrm{m}^{-2}\right)$. Data represent the mean of five replicates and error bars represent standard error. Means with the same letters are not significantly different (Tukey's HSD multiple comparisons at $p \leq 0.05$ ). Significant differences between session 2018 and 2019 plants are indicated by symbol '*' as obtained from unpaired $t$ test analysis

flowering and maturity were recorded in seedlings primed with $20 \mathrm{mg} \mathrm{l}^{-1} \mathrm{nZVI}$ (Table 2).

After analysis of plant morphological features like plant height, leaf area, it was revealed that there was a significant difference between the seedlings primed with nZVI compared to that of hydroprimed control sets. Maximum growth and leaf area increase were observed for the plants treated with $20 \mathrm{mg} \mathrm{l}^{-1} \mathrm{nZVI}$. However, in the 2nd year, overall plant growth and leaf area were reduced but in the nanoprimed sets, plant growth was still higher than the control hydroprimed sets (Fig. 5c and b).

Similar trends were also visible for plant biomass and panicle bearing effective tiller number. In both the year, seedlings primed with $20 \mathrm{mg}^{-1} \mathrm{nZVI}$, had a twofold increase in effective tiller numbers compared to that of the hydroprimed control set (Fig. 5c). Similarly, overall plant biomass was also significantly enhanced in the seedlings primed with $20 \mathrm{mg} \mathrm{l}^{-1} \mathrm{nZVI}$ (Fig. 5d).

Agronomic parameters like AGR, CGR, and NAR were estimated based on plant height, biomass, and leaf area to evaluate the growth of seedlings in different growth stages. AGR values on 30 and 60 DAS were higher in nanoprimed seedlings compared to the control plants. Maximum AGR value was obtained from seedlings primed with $20 \mathrm{mg} \mathrm{l}^{-1}$ nZVI. However, the AGR value declined significantly in the nanoprimed sets during the $3^{\text {rd }}$ harvest (Fig. 6a). On the other hand, CGR and NAR values in all the nanoprimed sets were higher than the control during all three harvest points (Fig. 6b and c).

\section{Yield Components}

Due to the increase in effective tiller number in the nanoprimed sets the total panicle amount also increased significantly compared to that of the control set. Panicle size, panicle weight, and the number of grains per panicles were significantly higher than control. The highest panicle number and weight were noted in the seedlings primed with $20 \mathrm{mg} \mathrm{l}^{-1}$ nZVI (Fig. 7a-d).

Additionally, hollow grain percentage was lower in the nanoprimed sets and panicles also had higher grain density compared to that of control (Fig. 8a, b). Seed weight and crop yield of nanoprimed seedlings were also improved with nZVI treatment. Around 1.34 fold and 3.8 fold increase in grain weight and grain yield respectively were observed in seedlings treated with $20 \mathrm{mg} \mathrm{l}^{-1} \mathrm{nZVI}$ (Fig. 8c, d).

\section{Kernel Qualities}

Concentration of phytochemicals in the rice grains obtained after seed priming varied significantly with respect to control sets in both the years. The total starch content varied with $\mathrm{nZVI}$ concentration $\left(y_{2018}=-0.0000\right.$ $9 x^{2}+0.0073 x+0.65 ; y_{2019}=-0.00004 x^{2}+0.0031 x+0.68$ $9)$. The maximum starch content was seen after $20 \mathrm{mg} \mathrm{l}^{-1}$ nZVI priming treatment and starch content of control set was similar with that of $80 \mathrm{mg} \mathrm{l}^{-1} \mathrm{nZVI}$ treatment sets. The total soluble sugar content also varied quadratically with nZVI concentration $\left(y_{2018}=-0.0075 x^{2}+0.5197 x+\right.$ $\left.36.679 ; y_{2019}=-0.0076 x^{2}+0.5319 x+35.888\right)$ (Fig. 9a and $\mathrm{b})$.

Other primary metabolites like protein and lipid contents also varied significantly with nanopriming. Protein and lipid contents also followed similar trends. The protein and lipid contents varied quadratically with nZVI concentrations and the peak reached after treatment with $20 \mathrm{mg} \mathrm{l}^{-1} \mathrm{nZVI}$ (Fig. 9c and d).

The secondary metabolite, phenol content, and thiamine, riboflavin, ascorbic acid (vitamin $\mathrm{B}_{1}, \mathrm{~B}_{2}$, and $\mathrm{C}$ ) levels were also estimated in the grains obtained after harvesting from the control and nanoprimed seedlings (Fig. 10a-d). Nanopriming could significantly modulate the grain secondary metabolite levels. The highest levels of phenol and all the vitamins were obtained in the $20 \mathrm{mg}^{-1} \mathrm{nZVI}$ treatment sets.

\section{Plant Mineral Content and Partition Coefficient Analysis}

Macronutrients ( $\mathrm{P}, \mathrm{K}, \mathrm{Ca}, \mathrm{Mg}, \mathrm{S})$ and micronutrient (Fe, $\mathrm{Mn}, \mathrm{Zn}$ ) concentrations were estimated from a plant root, shoot, and panicles. nZVI priming had an impact on mineral distribution and accumulation in different plant organs (Figs. 11 and 12). Nanopriming treatments were responsible for higher S, Ca, Mg, P, K, Mn, Zn, and Fe levels. Maximum grain mineral accumulation was obtained in the grains of $20 \mathrm{mg}^{-1} \mathrm{nZVI}$ primed seedlings. Nanopriming could significantly alter the proportional mineral content in an organ relative to the proportional dry weight of that organ as reflected by partition coefficient analysis (Table S1). It was found that the PQ value for root declined in the nanoprimed set whereas shoot and grain PQ value increased significantly. 

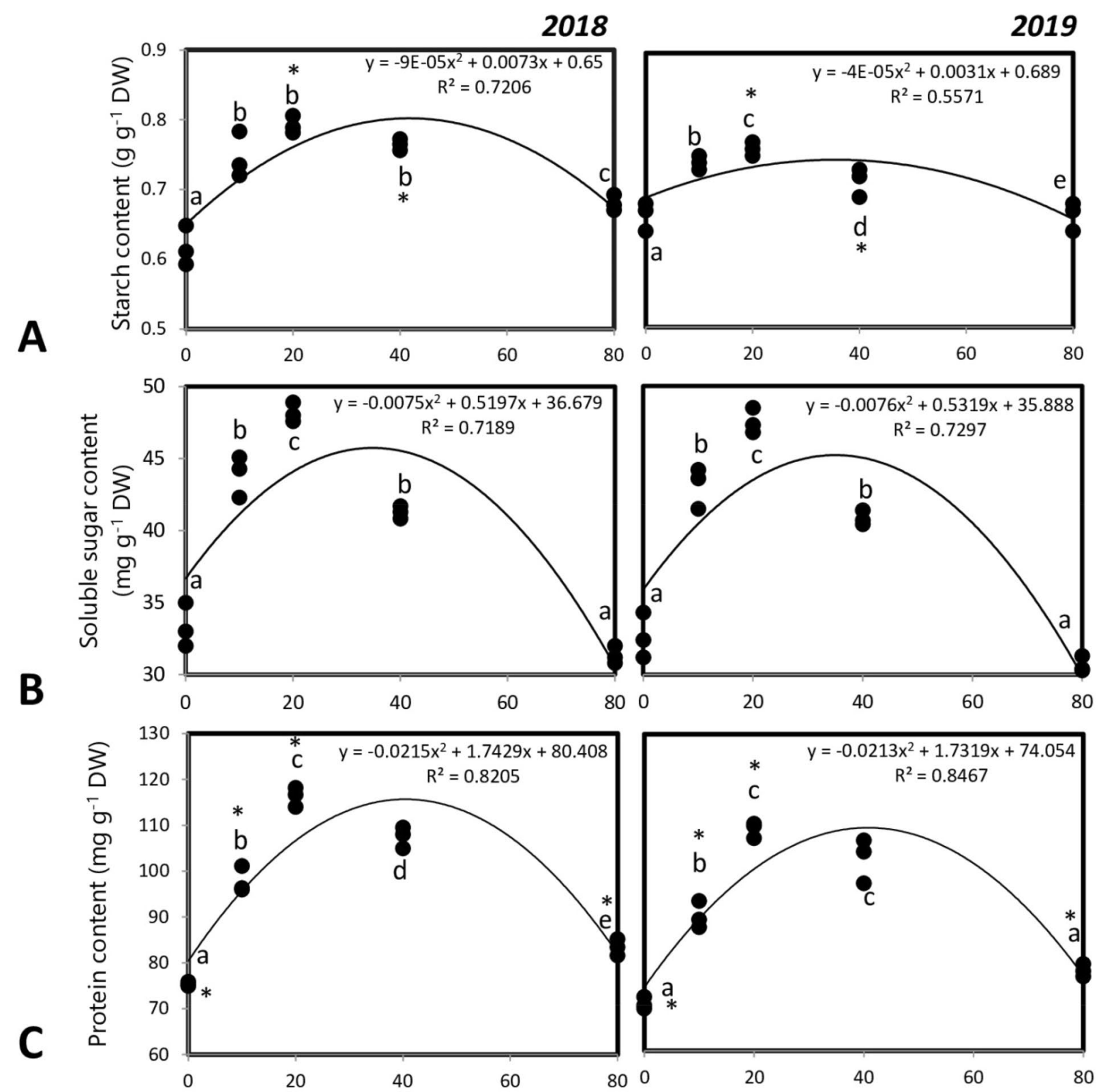

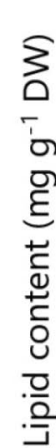

D
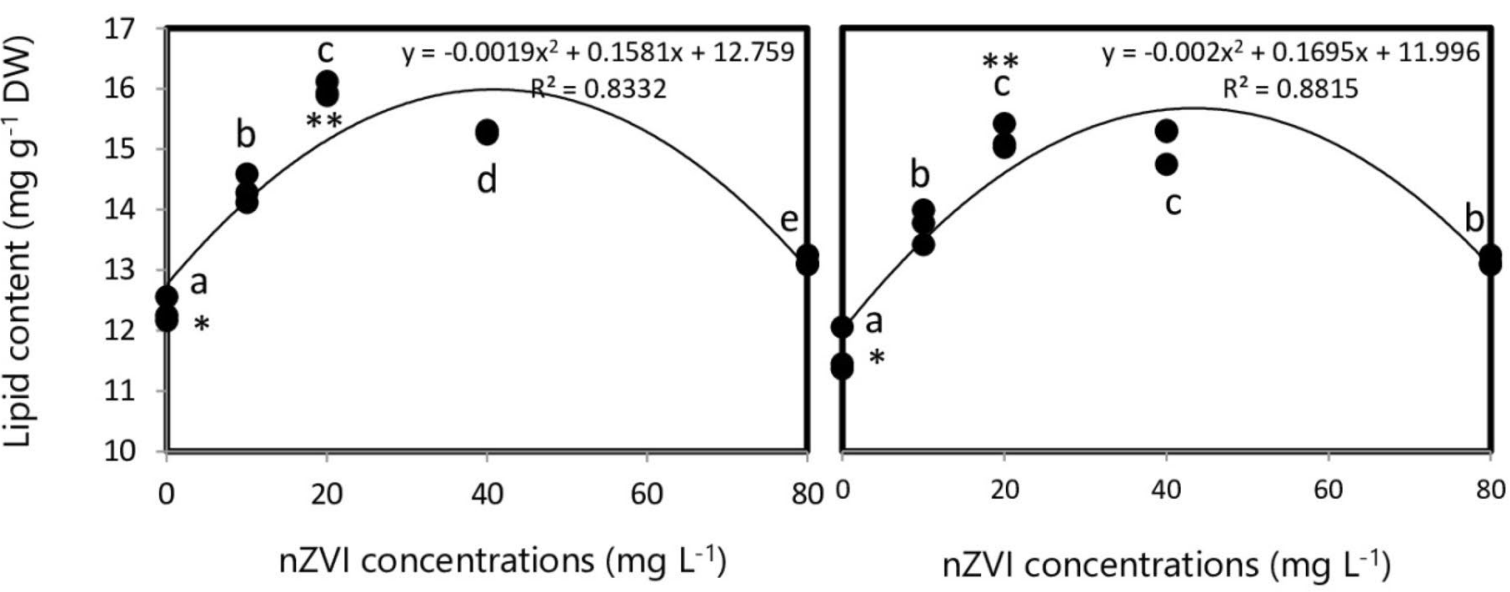
४Fig. 9 Influence of seed priming with different concentrations of nZVI on primary metabolite levels in rice grains a starch, b soluble sugar, c protein, d lipid. Data represents data of 3 replicates. Data with the same letters are not significantly different (Tukey's HSD multiple comparisons at $p \leq 0.05$ ). Significant differences between session 2018 and 2019 plants are indicated by symbol '*' as obtained from unpaired $t$ test analysis

\section{Correlation Analysis}

Pearson's correlation analyses were performed separately to find out relationships among 12 agronomic parameters and another correlation study was carried out to investigate the relationship among the early seedling characteristics, flowering and maturity period, and crop yield.

Among the agronomic traits positive correlations were observed among Plant height $(\mathrm{Ht})$, biomass $(\mathrm{Bm})$, leaf area (LA), effective tiller number (Et), Total panicle number per $\mathrm{m}^{-2}(\mathrm{Pn})$, panicle length (PL), panicle weight $(\mathrm{Pw})$, Grain density (Gd), number of seed per panicle (Sp) seed weight $(\mathrm{Sw})$ and total yield $(\mathrm{Yd})$. However, the results obtained from the 2018 study showed that seed weight was not significantly correlated to any of the agronomic traits but, results from 2019 reflected positive correlations. Negative correlations were found only for Hollow grain percentage (Hp) (Fig. 13a, b).

Seedling characteristics were directly correlated with crop yield (Yd). There was a positive correlation between $\mathrm{Yd}$ and final emergence percentage (FEP), root (RL), and shoot length (SL) of seedlings. On the other hand, mean emergence time (MET), flowering time (FL), and maturity time (Mt) were negatively correlated with Yd (Fig. 13c, d).

Pearson's correlation analysis was performed to evaluate the relationship between macro and micro-nutrient levels of seedlings after priming with different concentrations of nZVI. Negative correlations among the minerals were observed only in the root. Calcium was positively correlated with $\mathrm{Mn}$ and for other minerals, it had a negative correlation (Fig. 14a-c).

\section{Discussion}

In the context of sustainable agriculture, the application of nanoparticles is regarded to be one of the promising approaches due to its vast potential to revolutionize global agriculture and food production. Fe plays a significant role during seed germination. Deficiency of Fe in seeds can cause dormancy as well as impairs seed longevity (Murgia and Morandini 2017). In the present study, we found that seed priming with nZVI, significantly improved seedling establishment, growth, morphology and yield-related traits, kernel quality, and nutrient uptake capacity of rice.
According to our previous report, seed priming with nZVIcan up-regulate hydrolytic enzyme activities which accounted for increases in seedling vigor (Guha et al. 2018). Rapid and regulated utilization of metabolites improved seedling establishment in the primed sets (Basra et al. 2005). From the present results of the field study, we found that seed priming treatment could significantly reduce the mean emergence time (MET) and increase the final emergence percentage (FEP) of seedlings. Lower MET indirectly results in uniform emergence of seedlings in the nursery (Hampton and Tekrony 1995). The growth of nursery seedlings was increased significantly with nanopriming shown in Fig. S3. From the PPB stained images, it was confirmed that upon nZVI priming, the iron levels in the seeds increased in a dose-dependent manner. Although iron levels were found to be higher in the seeds treated with $40-80 \mathrm{mg}^{-1} \mathrm{nZVI}$, maximum growth enhancement was found in $20 \mathrm{mg} \mathrm{l}^{-1} \mathrm{nZVI}$ primed sets. This is chiefly attributed to the ROS concentration window. Since nZVI reacted with dissolved oxygen in the water and generate $\mathrm{ROS}$ (such as $\mathrm{H}_{2} \mathrm{O}_{2}$ and $\mathrm{OH}^{-}$), it plays an important role in modulating the ROS status of the seed (Keenan et al. 2009).ROS are key players in regulating seed germination and longevity and seed responses are strictly dependent upon ROS levels. If ROS concentration is below a certain threshold, the seed remains in a dormant stage and at the same time, if the ROS level is too high the seeds begin to lose viability because of oxidative stress. Thus upon treatment with $20 \mathrm{mg} \mathrm{l}^{-1} \mathrm{nZVI}$, the ROS concentration threshold was found to be optimum and hence maximum seed germination rate was found in the $20 \mathrm{mg} \mathrm{l}^{-1}$ nZVI treated set. SEM analysis revealed that nZVI induced no morphological damage on embryonic root tissue. RAPD banding also confirmed that low concentrations of nZVI do not induce DNA damage. Duration of flowering and maturity of nanoprimed seedlings were also reduced as a result of healthy and more vigorous seedling establishment. A positive correlation was observed between the growth of nursery seedlings and the yield obtained after maturity of field-grown plants, which is congruent with the findings of Farooq et al. (2007).

Plant architectural traits like, plant height, tiller number, and canopy characteristics are important agronomic traits that determine crop performance in the field and yield in rice (Mathan et al. 2016). Tillering is a key component of crop yield since it governs the number of panicles per plant (Xing and Zhang 2010), and tiller number in a plant is reported to be directly related to the vigor of nursery seedlings (Reddy 2004). Nanoprimed seedlings had a higher number of effective tillers per plant and increased plant height, biomass, and leaf area. A similar result was found upon priming spinach seeds with $\mathrm{FeS}_{2}$ nanoparticles where an increase in plant biomass and leaf area was observed upon seed treatment (Srivastava et al. 2014). 

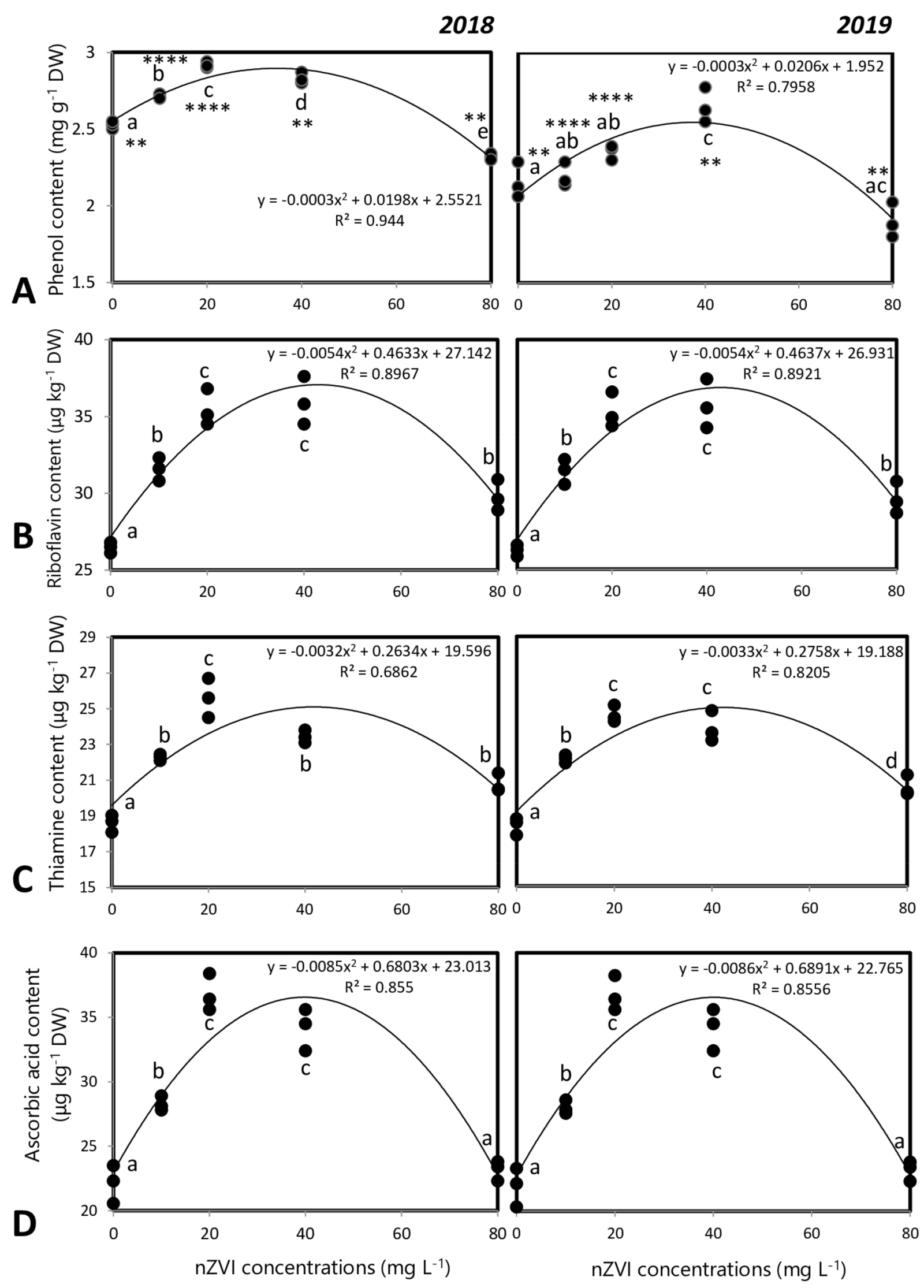
४Fig. 10 Influence of seed priming with different concentrations of nZVI on secondary metabolite levels in rice grains a phenol, b riboflavin, $\mathbf{c}$ thiamine, $\mathbf{d}$ Ascorbic acid. Data represents data of 3 replicates. Data with the same letters are not significantly different (Tukey's HSD multiple comparisons at $p \leq 0.05$ ). Significant differences between session 2018 and 2019 plants are indicated by symbol '*' as obtained from unpaired $t$ test analysis

Due to the increase in effective tiller number, the total panicle number per field area (in $\mathrm{m}^{2}$ ) was enhanced significantly. nZVI priming could also improve other yield-related characteristics such as panicle length, panicle weight, seed per panicle, hollow grain percentage. Seed priming treatment also enhanced grain yield which is also directly linked to healthier and vigorous seedling growth as proved by correlation analysis.

It was also observed that during the growth session of 2018, the maximum increase in yield and other agronomic characters were noted. This is mainly due to higher rainfall in session 2019 during September to October i.e. the reproductive phase. According to Abbas and Mayo (2020), increased rainfall during the flowering stage shows a negative relationship with rice production. This is mainly due to the effects of sediments in muddy water which block the pores and hampers respiration and photosynthesis, thus resulting in reduced production of the crop (Balasubramanian et al. 2004). However, it was found that nanoprimed seedlings could overcome the negative effects of heavy rainfall during reproductive stages and still showed higher crop yield compared to the control sets.

Plant growth parameters such as absolute growth rate (AGR), crop growth rate (CGR), and net assimilation rate (NAR) were estimated in different time points which reflect plant growth rates in different stages. AGR is a function of changes in plant height over a given time- period and it is directly dependent on environmental factors. AGR values were higher in nanoprimed seedlings compared to that of the control set during stem elongation and tillering stages. This suggests that healthier nursery seedlings from nanoprimed sets had the capacity for enhanced and earlier resource capture as compared to that of the control set (Farooq et al. 2007). However, CGR which indicates the change of dry weight over time was maximum during the flowering and maturity stages of the nanoprimed seedlings since they had higher yield capacity. NAR, on the other hand, correlates dry matter accumulation and leaf area of the plant which is an indicator of the plant's net photosynthetic effectiveness in capturing light, $\mathrm{CO}_{2}$ assimilation, and storage of photo-assimilates. NAR value was also higher during tiller and shoot-elongation stages but it declined during maturity because leaf area expansion rate generally reduces during this stage. However,nanoprimed seedlings had higher NAR value in all the 3-time points compared to the control plants which reflects enhanced photosynthetic efficiency.
According to Morales-Díaz et al. (2017), nanomaterials because of their unique physico-chemical properties can boost plant metabolism and crop nutritional quality. Hence, we further evaluated the grain nutrient status. In addition to starch, sugar, lipids, and proteins, Gobindobhog rice grains are rich in various essential phytochemicals such as phenol, ascorbic acid, thiamine, and riboflavin (Bhattacharyya and Roy, 2018). These phytochemicals are produced from secondary metabolism and are important bioactive compounds with antioxidant properties. Grains obtained from nanoprimed sets had higher phytochemical reserves compared to the control sets due to higher NAR value which indicates increased photo assimilation, and its translocation and partitioning to the grains (Farooq et al. 2007).

From ICP-AES results it was also found that nanopriming with different concentrations of nZVI could result in enhanced mineral uptake which resulted in higher mineral contents in grains. Similar results were also found by Srivastava et al. (2014), where nanopriming spinach seeds with $\mathrm{FeS}_{2}$ NPs could significantly increase the nutrient uptake capacity of plants. Significant increase in $\mathrm{Ca}, \mathrm{Mn}$, and $\mathrm{Zn}$ contents were reported in the nanoprimed plants which are congruent with our observations. The mineral uptake potential is mainly due to enhancement in root metabolism which was previously proved by Mahakham et al. (2017). However, the increase in mineral uptake such as $\mathrm{Ca}, \mathrm{Mg}, \mathrm{S}, \mathrm{P}$, and $\mathrm{K}$ lead to enhanced plant vigor. In addition to this increase in micronutrient content such as $\mathrm{Zn}$ had an immense role in increasing crop yield, Mn contributed in increasing photosynthesis and $\mathrm{Fe}$ also helped to boost plant metabolism and yield due to its role in embryogenesis. Significant correlations were observed among the mineral contents in the root, shoot, and panicles of nanoprimed sets. In most of the cases, positive correlations were observed due to the chemical similarity between the ions which allows competition for the site of absorption and transport in plants (Sperotto et al. 2012). Among all the minerals $\mathrm{Ca}$ in root showed a negative correlation which is similar to the observations of Sperotto et al. (2012). However, Ca content in shoot and grain showed positive correlations with other minerals.

Since any increase of mineral in a sink tissue (i.e. grain) must have been caused as a result of enhanced mineral uptake potential of the plant or from remobilization of minerals from one organ to another; the partition quotient (PQ) of each mineral was calculated. The PQ value allowed us to explore the changes in mineral distribution dynamics in nanoprimed sets. A decrease in PQ value in the root is generally associated with an increase in the remobilization of minerals to the aerial parts (Roriz et al. 2014). For Ca, K, P, and Mn decrease in PQ value in root were observed in the nanoprimed sets due to remobilization of these minerals from the root to aerial parts. According to Silveira et al. (2007), $\mathrm{Ca}$ and $\mathrm{K}$ concentrations in root generally decrease when 

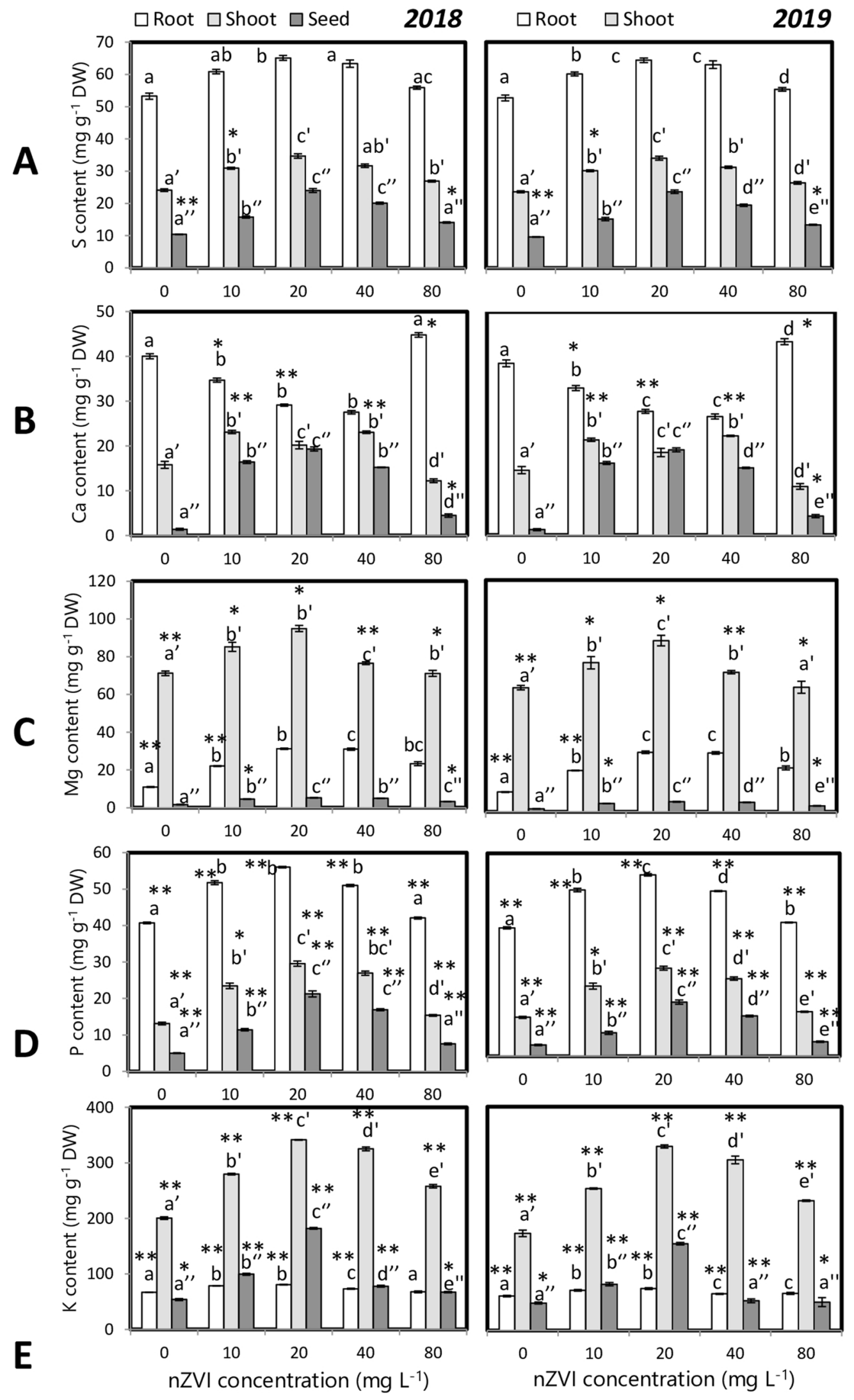
४Fig. 11 Influence of seed priming with different concentrations of nZVI on macronutrient levels in rice grains a $\mathrm{S}, \mathbf{b} \mathrm{Ca}, \mathbf{c ~} \mathrm{Mg}, \mathbf{d} \mathrm{P}$ and e K. Data represent data of 3 replicates. Data with the same letters are not significantly different (Tukey's HSD multiple comparisons at $p \leq 0.05$ ). Significant differences between session 2018 and 2019 plants are indicated by symbol '*' as obtained from unpaired $t$ test analysis

Fe levels are sufficient. Hence, we found a decrease in the $\mathrm{PQ}$ value of $\mathrm{Ca}$ and $\mathrm{K}$ in roots along with an increase in PQ value in rice shoots and grains. Several reports also claim that $\mathrm{P}$ remobilization occurs during later stages of growth if sufficient $\mathrm{P}$ has been absorbed by the plants during early growth stages (Grant et al. 2001). Thus it can be inferred that nanoprimed seedlings had proper $\mathrm{P}$ nutrition during the early stages, hence at maturity, root PQ value declined due to $\mathrm{P}$ remobilization. $\mathrm{Mn}$ is also an essential trace element that has a major role in photosynthesis (Socha and Guerinot 2014). Hence increased remobilization of root $\mathrm{Mn}$ to aerial parts

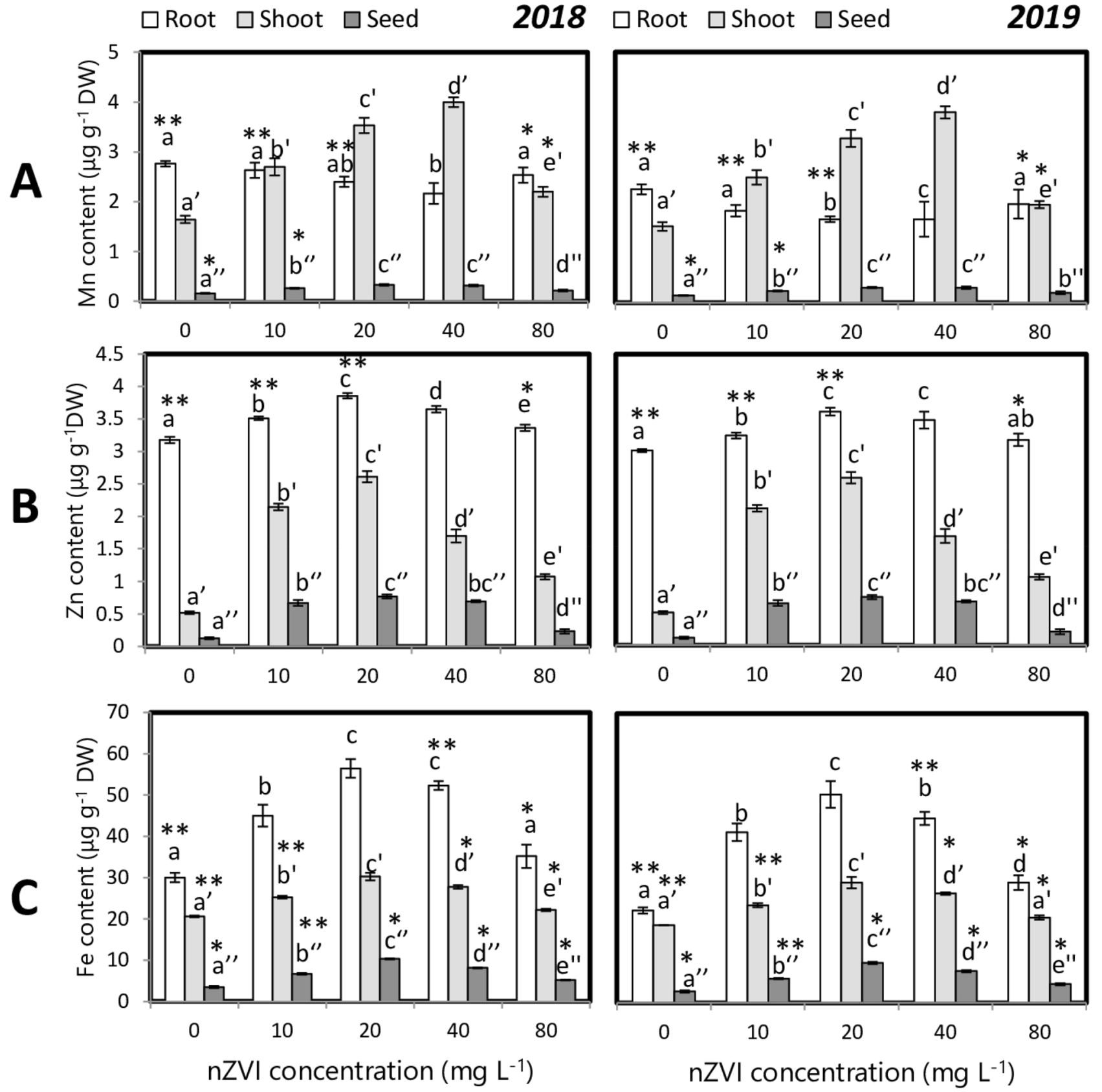

Fig. 12 Influence of seed priming with different concentrations of nZVI on macronutrient levels in rice grains a Mn, b Zn, and $\mathbf{c} \mathrm{Fe}$. Data represents data of 3 replicates. Data with the same letters are not significantly different (Tukey's HSD multiple comparisons at $p \leq 0.05)$. Significant differences between session 2018 and 2019 plants are indicated by symbol ' $*$ ' as obtained from unpaired $t$ test analysis 


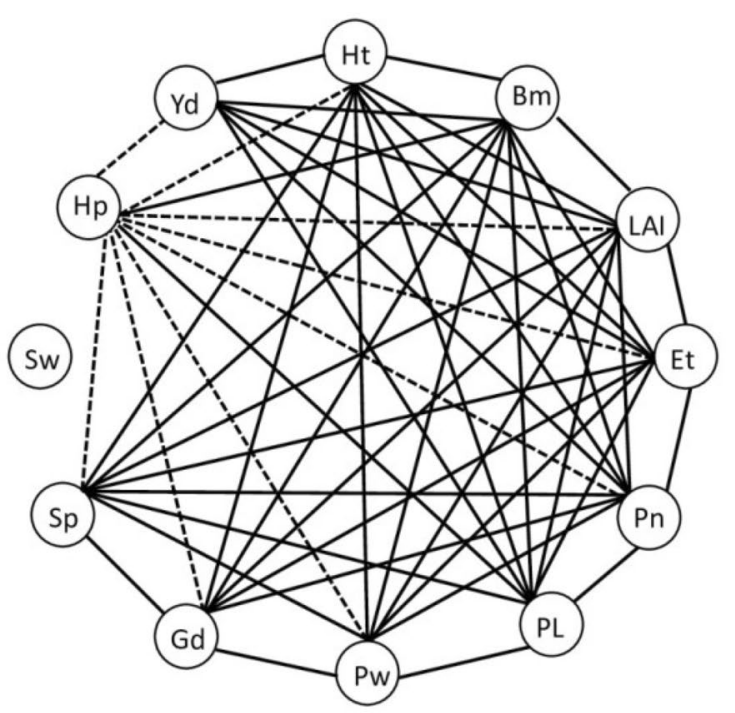

A

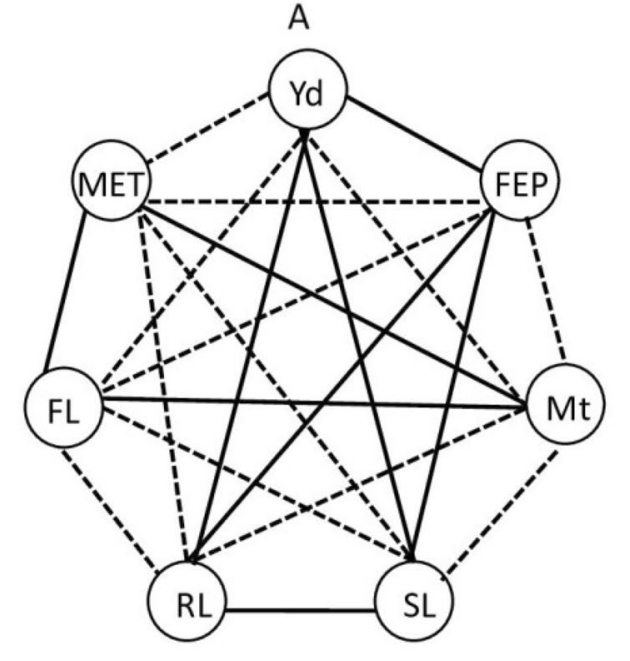

C

Fig. 13 Agronomic traits correlation analyses. a, b Pearson's correlation analysis of 12 agronomic characters obtained after maturity for session 2018 and 2019 respectively. C-D. Pearson's correlation analysis of 7 agronomic characters obtained from seedlings for session 2018 and 2019 respectively for rice plants cultivated after nanopriming seeds with different concentrations of nZVI. Solid lines represent a significant positive correlation and dashed lines represent a significant negative correlation. Thinner lines indicate significance at the

of nanoprimed plants played an important role in increasing plant photosynthetic efficiency.

$\mathrm{PQ}$ value for other minerals like, $\mathrm{Mg}, \mathrm{S}, \mathrm{Fe}$, and $\mathrm{Zn}$ was higher in all the plant organs of nanoprimed sets compared to that of control. Thus it is evident that nutrient uptake from soil was also enhanced due to nanopriming. An increase in $\mathrm{Mg}$ uptake can be explained by the positive interaction between $\mathrm{P}$ and $\mathrm{Mg}$ has been reported by Fageria (2001). $\mathrm{Mg}$ is an activator of kinase enzymes and activates phosphate transfer reactions. Nanopriming with nZVI enhanced the uptake of both Fe and S. It can

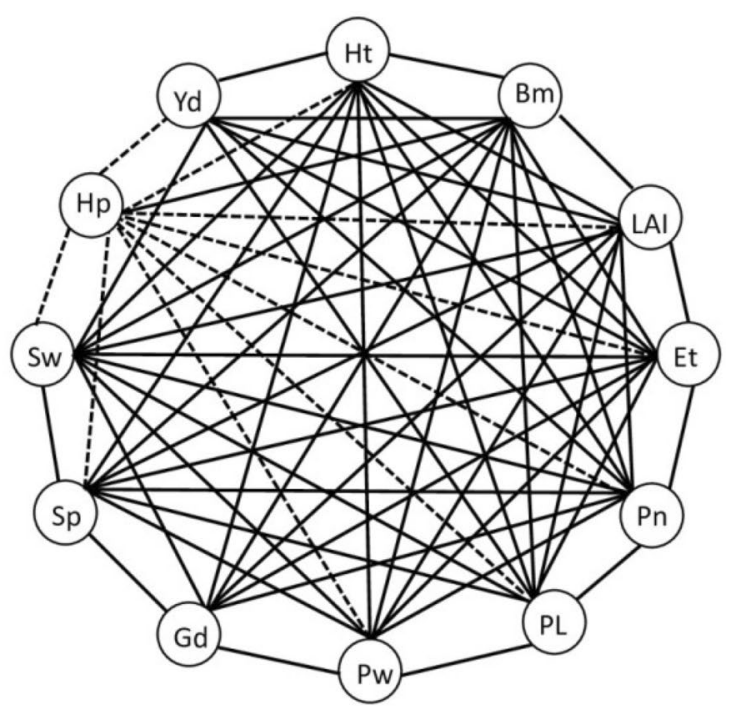

B

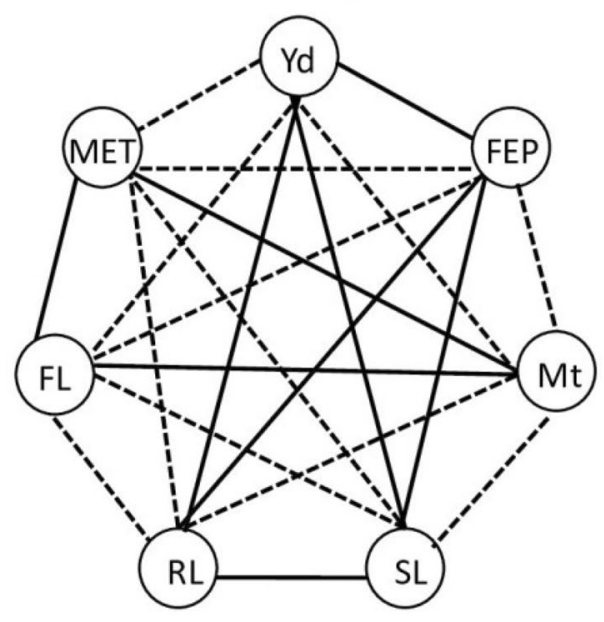

D

0.05 level and thicker lines indicate significance at the 0.01 level $(\mathrm{Ht}$ : Plant height, Bm: biomass, LA: leaf area, Et: effective tiller number, Pn: total panicle number per $\mathrm{m}^{-2}$, PL: panicle length, Pw: panicle weight, Gd: grain density, Sp: number of seed per panicle, Sw: seed weight, FEP: final emergence percentage, RL: root length, SL: shoot length. MET: mean emergence time, FL: flowering time, Mt: maturity time, and Yd: total yield)

be said that the external supply of nZVI helped to maintain $\mathrm{Fe}$ homeostasis which also stimulates the $\mathrm{S}$ uptake as proposed by Zuchi et al. (2015). The demand for the biosynthesis of $\mathrm{Fe}-\mathrm{S}$ clusters in the organelles produces a feedback signal that regulates the uptake of both $\mathrm{Fe}$ and S (Balk and Pilon 2011). Our study also showed an increase in $\mathrm{Zn}$ uptake which is in accordance with the finding of Silveira et al. (2007) which also showed a positive correlation between Fe and $\mathrm{Zn}$. Thus it can be said that nanopriming helped in the enrichment of all the essential 
Fig. 14 Pearson's correlation analysis of 8 mineral concentrations in grains (a i-ii), shoot (b i-ii), and root (c i-ii), of rice plants grown for session 2018 and 2019 respectively after nanopriming seeds with different concentrations of nZVI. Solid lines represent a significant positive correlation and dashed lines represent a significant negative correlation. Thinner lines indicate significance at the 0.05 level and thicker lines indicate significance at the 0.01 level
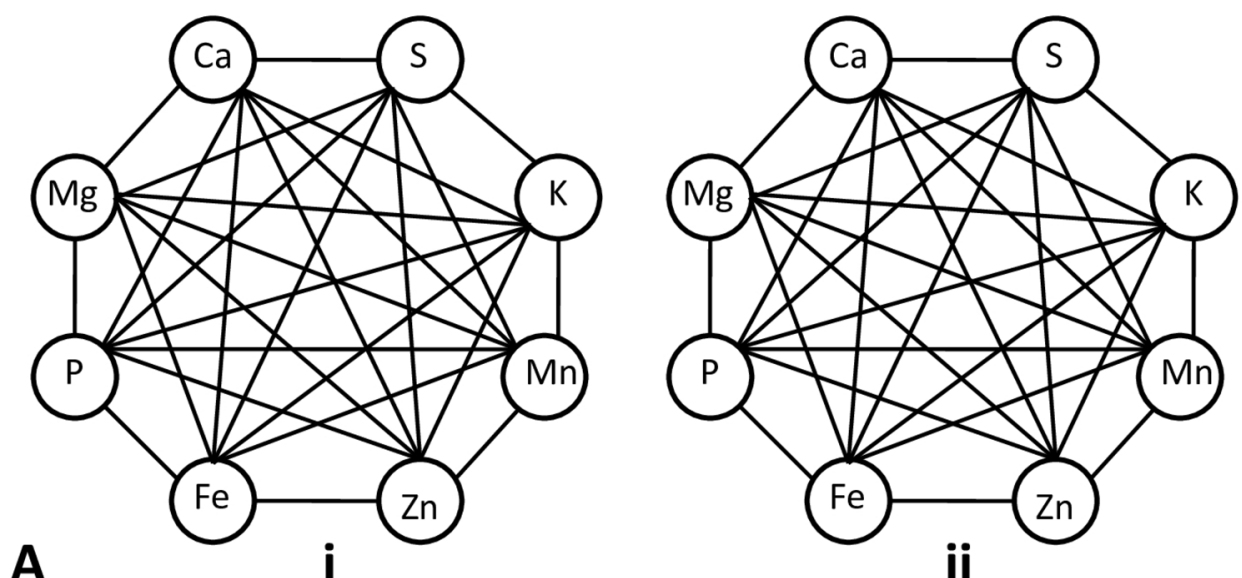

A
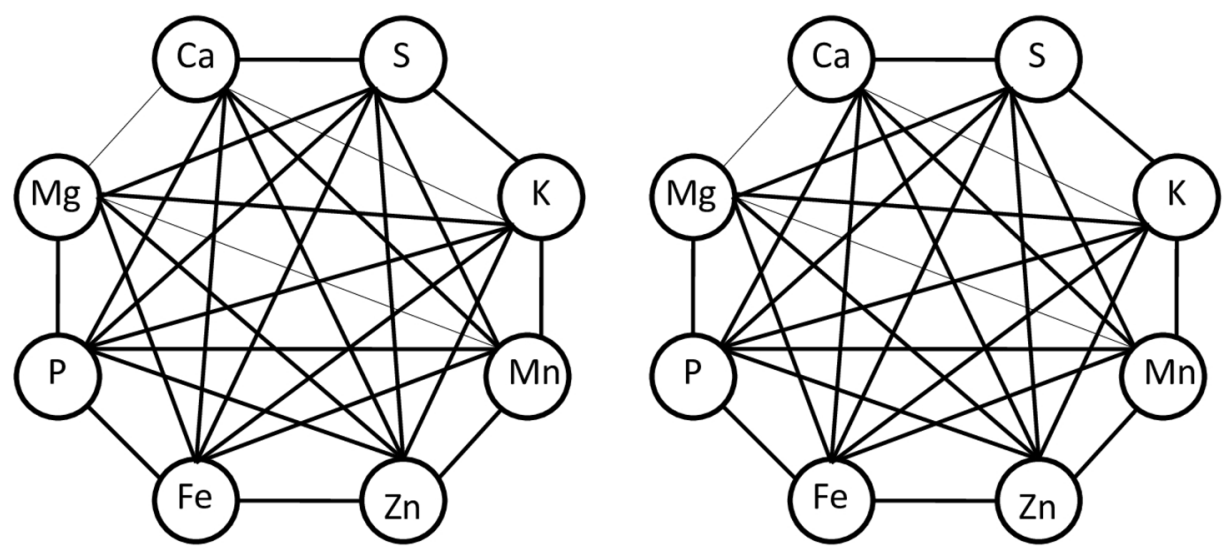

B

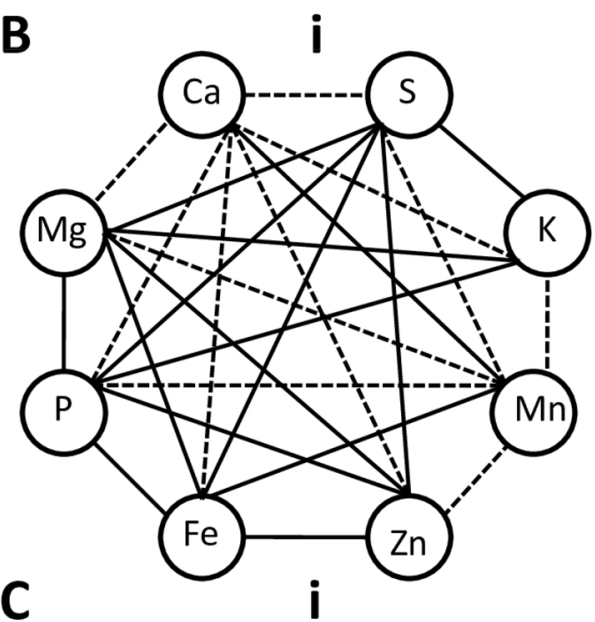

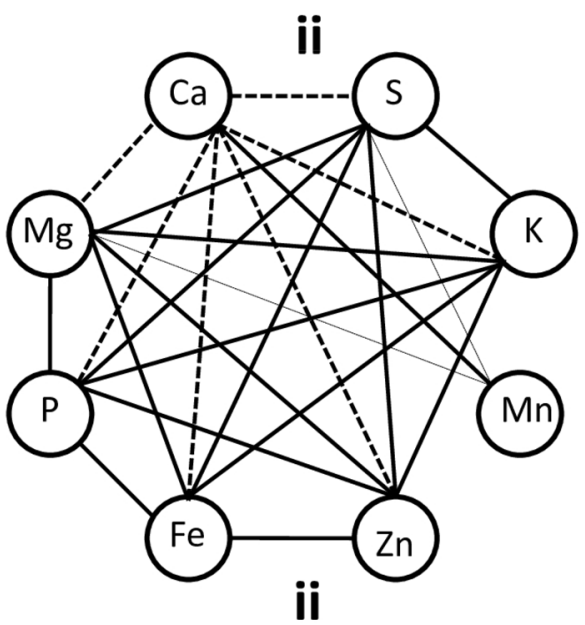

macro- and micronutrients which resulted in improved crop performances.

Lastly, from our results, it can be suggested that a low concentration of nZVI acted as a suitable priming agent of the seeds. Priming with $20 \mathrm{mg} \mathrm{l}^{-1} \mathrm{nZVI}$ had the maximum potential to increase crop yield. According to Rout and Sahoo (2015), iron is a prosthetic group for several enzymes (like cytochrome, catalase, and peroxidase) and thus plays various roles in metabolic processes like DNA synthesis, respiration, and photosynthesis. Iron also plays a significant role in the germination and development of the embryo as a result of which germination rate escalated in the nanoprimed sets. Nanopriming up-regulated plant photosynthetic efficiency and metabolism which is evident from high NAR values. Since iron plays an important role in chlorophyll synthesis, an increase in photosynthetic pigment content was found in nZVI primed seed as reported earlier by us (Guha et al. 2018). Due to the up-regulation of photosynthetic efficiency and plant metabolism, rice grains also had higher concentrations of phytochemicals which increased 
their nutritive value. The elemental analysis also proved that nZVI promoted nutrient uptake which played a major role in increasing crop yield. Thus, it can be concluded that seed priming with nZVI can increase rice yield compared to that of hydroprimed seeds without the addition of NPK fertilizers. Seed priming induced synchronized germination of seedlings and enhanced seedling vigor. Enhancement of metabolic activities of seeds before their journey in the soil also improved crop performance, nutrient assimilation capacity in later stages. This seed treatment process will help to cut down the fertilizer usage to some extent since crop yield was increased significantly with a seed treatment. Thus nZVI has a promising prospect in agriculture as a nanopriming agent or 'pro-fertilizer'. The application of nZVI can reduce the fertilizer footprints on our planet and prevent soil and water pollution due to fertilizer leaching. However, further field researches on the application of nZVI as a vehicle for pesticide or insecticide delivery and the role of nZVI in crop protection, stress tolerance are yet to be explored.

Supplementary Information The online version contains supplementary material available at https://doi.org/10.1007/s00344-021-10335-0.

Acknowledgements CAS, DST-FIST Department of Botany, Calcutta University, supported this research by providing infrastructural and instrumentation facilities. The authors are thankful to the University of Calcutta for the instrumentation facilities and for providing plots for field study. The authors also acknowledge IIT Bombay for ICP/AES analysis. TG thanks CSIR, Government of India for her fellowship.

Author Contributions Conceptualization, TG, AM and RK; methodology, TG; investigation, TG; writing - original draft, TG; writingreview \& editing, TG, AM and RK; funding acquisition, RK; resources, $\mathrm{AM}$ and RK; supervision, AM and RK.

Data Availability All data generated or analyzed during this study are included in this published article.

\section{Compliance with Ethical Standards}

Conflict of interest The authors declare that they have no conflict of interest.

\section{References}

Abbas S, Mayo ZA (2020) Impact of temperature and rainfall on rice production in Punjab, Pakistan. Environ Dev Sustain 25:1-23. https://doi.org/10.1007/s10668-020-00647-8

Anand KV, Anugraga AR, Kannan M, Singaravelu G, Govindaraju $\mathrm{K}$ (2020) Bio-engineered magnesium oxide nanoparticles as nano-priming agent for enhancing seed germination and seedling vigour of green gram (Vigna radiata L.). Mater Lett. https://doi. org/10.1016/j.matlet.2020.127792

Atienzar FA, Jha AN (2006) The random amplified polymorphic DNA (RAPD) assay and related techniques applied to genotoxicity and carcinogenesis studies: a critical review. Mutat Res 613:76-102
Balasubramanian MK, Bi E, Glotzer M (2004) Comparative analysis of cytokinesis in budding yeast, fission yeast and animal cells. Curr Biol 14(18):R806-818. https://doi.org/10.1016/j.cub.2004.09.022

Balk J, Pilon M (2011) Ancient and essential: the assembly of ironsulfur clusters in plants. Trends Plant Sci 16(4):218-226. https:// doi.org/10.1016/j.tplants.2010.12.006

Basra SMA, Farooq M, Tabassum R (2005) Physiological and biochemical aspects of seed vigour enhancement treatments in fine rice (Oryza sativaL.). Seed Sci Technol 33:623-628

Bewley JD, Bradford KJ, Hilhorst HWM, Nonogaki H (2013) Seeds. Physiology of development, germination and dormancy, 3rd edn. Springer, New York

Bhattacharyya S, Roy S (2018) Qualitative and quantitative assessment of bioactive phytochemicals in gobindobhog and black rice, cultivated in West Bengal, India. Int J Pharm Sci Res 9(9):3845-3851. https://doi.org/10.13040/IJPSR.0975-8232.9(9).3845-51

Das B, Sahoo RN, Pargal S et al (2018a) Quantitative monitoring of sucrose, reducing sugar and total sugar dynamics for phenotyping of water-deficit stress tolerance in rice through spectroscopy and chemometrics. Spectrochim Acta B 192:41-51. https://doi. org/10.1016/j.saa.2017.10.076

Das CK, Jangir H, Kumar J et al (2018b) Nano-pyrite seed dressing: a sustainable design for NPK equivalent rice production. Nanotechnol Environ Eng 3(1):14. https://doi.org/10.1007/ s41204-018-0043-1

Delfani M, Firouzabadi MB, Farrokhi N, Makarian H (2014) Some physiological responses of black-eyed pea to iron and magnesium nanofertilizers. Commun Soil Sci Plant Anal 45(4):530540. https://doi.org/10.1080/00103624.2013.863911

Doyle JJ, Doyle JL (1987) A rapid DNA isolation procedure for small quantities of fresh leaf tissue. Phytochem Bull 19:11-15

Ellis RA, Roberts EH (1981) The quantification of ageing and survival in orthodox seeds. Seed Sci Technol 9:373-409

Fageria VD (2001) Nutrient interactions in crop plants. J Plant Nutr 24(8):1269-1290

FAO (Food and Agriculture Organization of the United Nations) (2009) How to feed the world in 2050. Proceedings of the expert meeting on how to feed the world in 2050, 24-26 June 2009. FAO Headquarters, Rome

Farooq MSMA, Basra SMA, Ahmad N (2007) Improving the performance of transplanted rice by seed priming. Plant Growth Regul 51(2):129-137. https://doi.org/10.1007/s10725-006-9155-x

Ghule PL, Dahiphale VV, Jadhav JD et al (2013) Absolute growth rate, relative growth rate, net assimilation rate as influenced on dry matter weight of Bt cotton. Int Res J Agric Econ Stat $4(1): 42-46$

Gimeno-García E, AndreuV BR (1996) Heavy metals incidence in the application of inorganic fertilizers and pesticides to rice farming soils. Environ Pollut 92(1):19-25. https://doi.org/10.1016/02697491(95)00090-9

Grant CA, Flaten DN, TomasiewiczDJ SSC (2001) The importance of early season phosphorus nutrition. Can J Plant Sci 81(2):211-224. https://doi.org/10.4141/P00-093

Grillet L, Ouerdane L, Hoang MTT et al (2013) Ascorbate efflux as a new strategy for iron reduction and transport in plants. J Biol Chem 289(5):2515-2525. https://doi.org/10.1074/jbc. M113.514828

Guha T, Ravikumar KV, Mukherjee A, Kundu R (2018) Nanopriming with zero valent iron (nZVI) enhances germination and growth in aromatic rice cultivar (Oryza sativa cv. Gobindabhog L.). Plant Physiol Biochem 127:403-413. https://doi.org/10.1016/j.plaph y.2018.04.014

Hampton JG, Tekorny DM (1995) Handbook of ISTA vigour test methods, 3rd edn. ISTA, Zurich 
Hunt R (1979) Plant growth analysis: the rationale behind the use of the fitted mathematical function. Ann Bot 43(2):245-249

Itroutwar PD, Govindaraju K, Tamilselvan S et al (2019) Seaweedbased biogenic $\mathrm{ZnO}$ nanoparticles for improving agro-morphological characteristics of rice (Oryza sativa L.). J Plant Growth Regul 5:1-2. https://doi.org/10.1007/s00344-019-10012-3

Keenan CR, Goth-Goldstein R, Lucas D et al (2009) Oxidative stress induced by zero-valent iron nanoparticles and $\mathrm{Fe}(\mathrm{II})$ in human bronchial epithelial cells. Environ Sci Technol 43:4555-4560. https://doi.org/10.1007/s11051-008-9446-4

Li X, Yang Y, Gao B et al (2015) Stimulation of peanut seedling development and growth by zero-valent iron nanoparticles at low concentrations. PLoS ONE 10(4):e0122884. https://doi. org/10.1371/journal.pone.0122884

Lowry OH, Rosebrough NJ, Farr AL et al (1951) Protein measurement with the Folin phenol reagent. J Biol Chem 193:265-275

Mahakham W, Sarmah AK, Maensiri S et al (2017) Nanopriming technology for enhancing germination and starch metabolism of aged rice seeds using phytosynthesized silver nanoparticles. Sci Rep 7(1):1-21. https://doi.org/10.1038/s41598-017-08669-5

Mathan J, Bhattacharya J, Ranjan A (2016) Enhancing crop yield by optimizing plant developmental features. Development 143(18):3283-3294. https://doi.org/10.1242/dev.134072

Mirshekari B (2015) Physical seed treatment techniques may influence stand establishment and yield of wheat in delayed cropping. Idesia 33(3):49-54

Morales-Díaz AB, Ortega-Ortíz H, Juárez-Maldonado A et al (2017) Application of nanoelements in plant nutrition and its impact in ecosystems. Adv Nat Sci-Nanosci Nanotechnol 8(1):013001. https://doi.org/10.1088/2043-6254/8/1/013001

Mukherjee AK, Tripathi S, Mukherjee S et al (2019) Effect of integrated nutrient management in sunflower (Helianthus annuus L.) on alluvial soil. Curr Sci 117(8):1364. https://doi. org/10.18520/cs/v117/i8/1364-1368

Murgia I, Morandini P (2017) Iron deficiency prolongs seed dormancy in Arabidopsis plants. Front Plant Sci 8:2077. https:// doi.org/10.3389/fpls.2017.02077

Nadeem F, Farooq M, Ullah A et al (2019) Influence of Zn nutrition on the productivity, grain quality and grain biofortification of wheat under conventional and conservation rice-wheat cropping systems. Arch Agron Soil Sci. https://doi.org/10.1080/03650 340.2019.1652273

Nandagoapalan V, Doss A, Marimuthu C (2016) Phytochemical analysis of some traditional medicinal plants. Biosci Discov 7:17-20

Okolie NP, Falodun A, Davids O (2014) Evaluation of the antioxidant activity of root extract of pepper fruit (Dennetiatripetala), and it's potential for the inhibition of lipid peroxidation. Afr J Tradit Complem Altern Med 11(3):221-227. https://doi.org/10.4314/ ajtcam.v11i3.31

Otero N, Vitoria L, Soler A et al (2005) Fertilisercharacterisation: major, trace and rare earth elements. Appl Geochem 20(8):14731488. https://doi.org/10.1016/j.apgeochem.2005.04.002

Palaniswamy KM, Gomez KA (1974) Length-width method for estimating leaf area of rice. Agron J 66(3):430-433. https://doi. org/10.2134/agronj1974.00021962006600030027x

Paparella S, Araújo SS, Rossi G et al (2015) Seed priming: state of the art and new perspectives. Plant Cell Rep 34:1281-1293. https:// doi.org/10.1007/s00299-015-1784-y

Poudel PB, Poudel MR, Gautam A et al (2020) COVID-19 and its global impact on food and agriculture. J Biol Today's World 9(5):221

Ravikumar KVG, Dubey S, Pulimi M et al (2016) Scale-up synthesis of zero-valent iron nanoparticles and their applications for synergistic degradation of pollutants with sodium borohydride. J Mol Liq 224:589-598. https://doi.org/10.1016/j.molli q.2016.10.040

Reddy S (2004) Agronomy of field crops. Kalyani Publishers, New Delhi

Rehman HU, Basra SMA, Farooq M (2011) Field appraisal of seed priming to improve the growth, yield, and quality of direct seeded rice. Turk J Agric For 35(4):357-365. https://doi.org/10.3906/ tar-1004-954

Roriz M, Carvalho SM, Vasconcelos MW (2014) High relative air humidity influences mineral accumulation and growth in iron deficient soybean plants. Front Plant Sci 5:726. https://doi. org/10.3389/fpls.2014.00726

Roschzttardtz H, Conèjèro G, Divol F et al (2013) New insights into Fe localization in plant tissues. Front Plant Sci 4:350. https://doi. org/10.3389/fpls.2013.00350

Rout GR, Sahoo S (2015) Role of iron in plant growth and metabolism. Rev Agric Sci 3:1-24. https://doi.org/10.7831/ras.3.1

Rui M, Ma C, Hao Y et al (2016) Iron oxide nanoparticles as a potential iron fertilizer for peanut (Arachishypogaea). Front Plant Sci 7:815. https://doi.org/10.3389/fpls.2016.00815

Shinde S, Paralikar P, Ingle AP, Rai M (2020) Promotion of seed germination and seedling growth of Zea mays by magnesium hydroxide nanoparticles synthesized by the filtrate from Aspergillus niger. Arab J Chem 13(1):3172-3182. https://doi.org/10.1016/j. arabjc.2018.10.001

Silveira VCD, Oliveira APD, Sperotto RA et al (2007) Influence of iron on mineral status of two rice (Oryza sativa L.) cultivars. Braz J Plant Physiol 19(2):127-139. https://doi.org/10.1590/S1677 $-04202007000200005$

Socha AL, Guerinot ML (2014) Mn-euvering manganese: the role of transporter gene family members in manganese uptake and mobilization in plants. Front Plant Sci 5:106. https://doi.org/10.3389/ fpls.2014.00106

Sperotto RA, Vasconcelos MW, Grusak MA et al (2012) Effects of different Fe supplies on mineral partitioning and remobilization during the reproductive development of rice (Oryza sativa L.). Rice 5(1):27. https://doi.org/10.1186/1939-8433-5-27

Srivastava G, Das CK, Das A et al (2014) Seed treatment with iron pyrite $\left(\mathrm{FeS}_{2}\right)$ nanoparticles increase the production of spinach. RSC Adv 4:58495-58504. https://doi.org/10.1039/C4RA06861K

Su L, Yin JJ, Charles D et al (2007) Total phenolic contents, chelating capacities, and radical-scavenging properties of black peppercorn, nutmeg, rosehip, cinnamon and oregano leaf. Food Chem 100(3):990-997. https://doi.org/10.1016/j.foodchem.2005.10.058

UN (United Nations Department of Economic and Social Affairs, Population Division) (2013) World Population Prospects: the 2012 Revision

Wang Z, Cuschieri A (2013) Tumour cell labelling by magnetic nanoparticles with determination of intracellular iron content and spatial distribution of the intracellular iron. Int J Mol Sci 14:9111-9125

Waters BM, Grusak MA (2008) Whole-plant mineral partitioning throughout the life cycle in Arabidopsis thaliana ecotypes Columbia, Landsbergerecta, Cape Verde Islands, and the mutant line ysl1ysl3. New Phytol 177(2):389-405. https://doi.org/10.11 11/j.1469-8137.2007.02288.x

Xing Y, Zhang Q (2010) Genetic and molecular bases of rice yield. Annu Rev Plant Biol 61:421-442. https://doi.org/10.1146/annur ev-arplant-042809-112209

Yoon H, Kang YG, Chang YS et al (2019) Effects of zerovalent iron nanoparticles on photosynthesis and biochemical adaptation of soil-grown Arabidopsis thaliana. Nanomaterials 9(11):1543. https ://doi.org/10.3390/nano9111543

Yugandhar P, Savithramma N (2013) Green synthesis of calcium carbonate nanoparticles and their effects on seed germination 
and seedling growth of Vigna mungo (L.) Hepper. Int J Adv Res 1(8):89-103

Zuchi S, Watanabe M, Hubberten HM et al (2015) The interplay between sulfur and iron nutrition in tomato. Plant Physiol 169(4):2624-2639. https://doi.org/10.1104/pp.15.00995
Publisher's Note Springer Nature remains neutral with regard to jurisdictional claims in published maps and institutional affiliations. 